\title{
QUANDO O CONTEXTO IMPORTA \\ Análise do turnover ministerial na Argentina e no Brasil após a redemocratização
}

\section{Renato Perissinotto (1)}

(D) https://orcid.org/0000-0001-8747-7976

Adriano Codato

(D) https://orcid.org/0000-0002-5015-4273

Mariana Gené ${ }_{3)}$

(D) https://orcid.org/0000-0002-7699-7121

(1) Professor no Programa de Pós-Graduação em Ciência Política da Universidade Federal do Paraná (UFPR), Curitiba - PR, Brasil; pesquisador do CNPq. E-mail: monseff@gmail.com

(2) Professor no Programa de Pós-Graduação em Ciência Política da Universidade Federal do Paraná (UFPR), Curitiba - PR, Brasil; pesquisador do CNPq. E-mail: adriano@ufpr.br

(3) Instituto de Altos Estudios Sociales da Universidad Nacional de San Martín, Consejo Nacional de Investigaciones Científicas y Técnicas (Conicet), Buenos Aires, Distrito Federal, Argentina; pesquisadora do Conicet. E-mail: mariana.gene@yahoo.com.ar

DOI: $10.1590 / 3510412 / 2020$

\section{Introdução}

O artigo compara Argentina e Brasil no período pós-ditatorial com o objetivo de identificar semelhanças e diferenças com relação à taxa de sobrevivência e às razóes de saída dos ministros de Estado. Mas por que estudar o turnover ministerial e por que comparar exatamente Argentina e Brasil?

Estudos sobre gabinetes em países presidencialistas tendem a focalizar variáveis que explicam o processo de recrutamento de ministros. No entanto, todo recrutamento tem no tempo de permanência dos recrutados e nas razóes pelas quais deixam os governos sua outra face. Por conseguinte, a compreensão de ambos os processos - hiring and firing - é necessária ao pleno entendimento do perfil e da evolução de gabinetes ministeriais. ${ }^{1}$

Artigo recebido em: 08/10/2019

Aprovado em: 22/01/2020
A comparação entre os dois países é especialmente relevante porque, na Argentina, não vigora um presidencialismo de coalizão entre diferentes partidos políticos, como no Brasil. O presidencialismo brasileiro - num contexto em que o partido do presidente dificilmente possuirá maioria no Congresso Nacional - obriga o chefe do governo a formar coalizóes político-partidárias amplas com o objetivo de aprovar as iniciativas legislativas do Executivo. Por esse apoio político, uma das moedas de troca do governo são posiçôes de comando em ministérios (e cargos na alta burocracia federal) para os indicados pelos partidos aliados. Nesse sentido, pertencer a um partido que integra a coalizão é uma variável privilegiada pelo presidente no momento de selecionar ministros. No presidencialismo argentino, diferentemente, o recrutamento é feito, em geral, ${ }^{2}$ nos quadros do partido do presidente, dispensando a formaçáo de coalizóes partidárias instáveis, mas obrigando o chefe do Executivo a lançar mão de variáveis de outra 
natureza para compor o seu gabinete. ${ }^{3}$ A comparação entre os dois casos poderia revelar singularidades importantes quanto à demissão de ministros nos dois maiores países da América do Sul em função, justamente, da natureza distinta de funcionamento dos seus respectivos regimes presidenciais.

$\mathrm{O}$ artigo propóe, assim, duas hipóteses a serem testadas para os dois países.

H1: A primeira hipótese supóe que os ministros no Brasil teriam um tempo de vida menor que na Argentina, em função da necessidade de, no primeiro caso, fazer frente a demandas de uma ampla coalizão partidária, sempre sujeita a mudanças impostas pela necessidade de o presidente buscar apoio em muitos parceiros políticos diferentes.

Como o número efetivo de partidos no Brasil não só é alto como consideravelmente aumentou ao longo do período posterior à redemocratização, faz sentido supor que a formação de uma maioria parlamentar razoavelmente estável exigiria mais atenção do presidente às demandas dos partidos, sobretudo no que diz respeito ao lugar deles no gabinete ministerial. Assim, quanto mais partidos no Parlamento, maior a necessidade de ampliar a coalizão e maiores os custos para geri-la. ${ }^{4}$

H2: A segunda hipótese sugere que as razóes de saida dos ministros do gabinete seriam essencialmente diferentes no Brasil e na Argentina justamente porque os critérios políticos de nomeação, em função do tipo de presidencialismo de cada país, são eles próprios distintos. No Brasil, as demissóes ministeriais estariam mais ligadas às reformas de gabinete, para reacomodar aliados, que na Argentina.

No Brasil, o pertencimento a um partido da base aliada é tido como um parâmetro importante na seleção dos ministros de Estado. ${ }^{5}$ No caso argentino, como ser membro do partido do presidente é um elemento quase invariante, os critérios de recrutamento são mais diversos, contando outros fatores, como proximidade pessoal com o chefe de governo, expertise (técnica ou política) para determinado portfólio, capacidade de representar grupos e coalizóes sociais próximas ao partido no governo etc. (De Luca, 2011; Camerlo, 2013; Gené, Heredia e Perelmiter, 2015; Gené, 2016; Ollier e Palumbo, 2016).
Para testar as duas hipóteses, o artigo se estrutura da seguinte maneira. Na primeira seção, fazemos uma breve revisão da literatura sobre motivos de demissóes e chances de sobrevivência de ministros nos gabinetes. Na segunda seção, listamos as fontes utilizadas para analisar a trajetória e as causas de saída dos ministros brasileiros e argentinos. $\mathrm{Na}$ terceira seção, investigamos as chances de sobrevivência dos ministros nos dois países, de maneira agregada. A quarta seção apresenta uma análise de dados de instabilidade ministerial por presidências nos dois países, enfatizando a importância de se levar em consideração o contexto político e econômico de cada governo para se verificar os problemas em questão. $\mathrm{Na}$ quinta seção, fazemos o mesmo com as razóes de saída do gabinete. A conclusão apresenta algumas rápidas consideraçóes sobre os achados do artigo.

As chances de sobreviver politicamente e as razões de saída dos gabinetes presidenciais parecem ter menos a ver com o desenho institucional dos dois presidencialismos e o tipo de exigência derivado do processo de formação de redes de apoios políticos e mais com as conjunturas específicas em que a demissão ocorre.

\section{Revisão da literatura}

Grande parte da literatura sobre o processo de formação de gabinetes ministeriais se preocupa com os motivos pelos quais ministros são escolhidos e, em particular, com os impactos dos arranjos tanto institucional como partidário sobre esse processo, uma vez que tendem a ser significativamente diferentes, dependendo de o governo ser unipartidário ou multipartidário. Segundo raciocínio difundido, é "preciso fazer uma distinção clara entre os governos de partido único e os governos de coalizão, uma vez que a margem de manobra dos chefes dos Executivos na contratação e demissão de ministros é, provavelmente, bastante diferente nesses dois tipos de contextos" (Dowding e Dumont, 2009, p. 15). ${ }^{6}$ Muitos estudos mostraram que o pertencimento partidário tende a predominar como critério político para o recrutamento em governos de coalizão multipartidos, sejam parlamentaristas, semipresidencialistas ou presidencialistas (Amorim Neto e Samuels, 2010; 
Blondel, Müller-Rommel e Malovà, 2007; Dowding e Dumont, 2009; Abranches, 1988; Amorim Neto, 1994; 2000; Batista, 2013; Inácio, 2013; Vasselai, 2009; Altman, 2000). ${ }^{7}$

Por outro lado, autores que exploraram a dinâmica de governos formados por um único partido procuraram mostrar como as características desse sistema obrigam o chefe de governo a levar em consideração critérios diferentes da mera origem partidária do ministro. Em sistemas parlamentaristas que geram governos monopartidários (como no Reino Unido), o gabinete nasce de negociaçóes e indicaçóes dentro do partido majoritário. Já no caso de presidencialismos de partido único (como na Argentina), cabe ao presidente escolher pessoalmente os nomes que vão ajudá-lo a governar. Nesse sentido, o partido de origem não é o critério mais relevante, ou o único critério, para a seleção de ministros (Pomares et al., 2014; Ollier e Palumbo, 2016; Gené, 2014; Camerlo, 2013; Gené, Heredia e Perelmiter, 2015; Giorgi, 2014; Huber e Martinez-Gallardo, 2004; Rose, 1971; Indridason e Kam, 2008).

Por sua vez, há importante literatura que orientou suas questóes menos para a relação entre arranjos partidários e formação de gabinetes e mais para as razóes de saídas do gabinete ministerial e o tempo de sobrevivência dos ministros nos seus cargos. Afinal, para entender plenamente o processo de "recrutamento ministerial", não basta saber apenas por que ministros entram em função como também por quanto tempo ficam e por que deixam o gabinete. Nesse universo há ao menos duas perspectivas diferentes.

Há, em primeiro lugar, estudos cuja preocupação é basicamente identificar e descrever as razões visíveis da saída, categorizando os diferentes motivos da troca de titular do portfólio ministerial (Dowding e Dumont, 2009; Costa Pinto e Tavares de Almeida, 2009; Camerlo, 2013). Em segundo lugar, há pesquisas preocupadas em analisar o tempo de permanência dos ministros nos seus cargos, conjugando a análise das razóes de saída, do tempo de sobrevivência dos ministros e das variáveis (institucionais, políticas, sociais, de carreira) que afetam as chances de dado ministro em dado governo permanecer no posto, valendo-se, para tanto, de instrumentos que medem tanto as razões de chance de sobrevivência como o poder de algumas variáveis explicativas (Berlinski, Dewan e Dowding, 2007; Huber e Martinez-Gallardo, 2008; González-Bustamante e Olivares, 2016b; Hansen et al., 2013; Scharfenkamp, 2018).

No que diz respeito ao problema dos tipos de razóes de saída, a literatura não difere muito entre si. Camerlo (2013), por exemplo, classifica-as da seguinte maneira: ineficiência no comando da pasta ministerial, escândalos, conflito com o Congresso, conflitos no interior do governo, eleições, reacomodaçôes políticas e categoria residual de "outros", incluindo problemas de saúde, mortes ou nomeaçóes interinas. No presidencialismo argentino, as demissões dos ministros de Estado indicam alta discricionariedade do presidente que, mesmo na ausência de conflitos, pode optar por mudar o seu ministério e nomear outro, seguindo lógicas não estritamente institucionais. Costa Pinto e Tavares de Almeida (2009) apresentam a seguinte lista para saídas antecipadas em seu estudo sobre gabinetes em Portugal: (mau) desempenho, desacordo em relação a políticas de governo, conflitos intrapartidários, erro departamental, escândalos, morte, erro pessoal, embate de personalidade, liderança partidária. Conforme o estudo, o que predomina como a principal razão de saída no gabinete português é a baixa performance do ministro. Indridason e Kam (2008) apresentam razóes similares, a saber, término do gabinete sem renomeação do titular da pasta, término do gabinete com renomeação, reordenação de gabinete (reshuffle) ou "reforma ministerial", renúncia, fim de nomeação provisória e morte. Dowding e Dumont (2009) são mais parcimoniosos em seus critérios e sugerem apenas três razóes para demissão do cargo: desacordo com a linha política do governo, escândalo pessoal ou político e renovação do gabinete.

Outros trabalhos são particularmente próximos do nosso artigo, pois conjugam o estudo das razóes de saída e suas causas com a análise das chances de sobrevivência dos ministros, lançando mão dos testes de Kaplan-Meier para medir esse fenômeno, tanto para os casos latino-americanos (González-Bustamante e Olivares, 2016a; Arellano González, Toro Maureira e Novoa Ocares, 2018) como para os de outros países (Berlinski, Dewan e Dowding, 2007; Quiroz Flores, 2009; Kerby, 2015). Com alguma variação, todos os 
autores têm como pano de fundo o contexto institucional em que sobrevivência no gabinete ou demissão dele ocorrem em sistemas presidencialistas e em sistemas semipresidencialistas. De maneira mais ou menos explícita se estabelece algum tipo de relação entre o arranjo institucional, as chances de sobrevivência e as razóes de saída do cargo.

O presente artigo coincide com esses objetivos, mas é importante frisar que não pretendemos apresentar uma explicação causal para as chances de sobrevivência e para as razóes de saída dos ministros brasileiros e argentinos, e sim interpretá-las à luz das diferenças institucionais e contextuais entre os dois presidencialismos.

\section{Fontes e métodos de codificação}

Os dados coletados para esta pesquisa foram retirados de diversas fontes.

No caso brasileiro, foram consultados a Biblioteca da Presidência da República ${ }^{8}$ para determinar datas exatas de entrada e saída do gabinete, o Dicionário histórico-biográfico brasileiro, publicado pelo Centro de Pesquisa e Documentação de História Contemporânea do Brasil (CPDOC), ${ }^{9}$ para as biografias dos ministros, e a Wikipedia, ${ }^{10}$ quando não havia informações suficientes no dicionário. De maneira complementar, quando as informaçóes acerca das razóes da saída dos ministros brasileiros não ficavam claras nessas três fontes indicadas, recorreu-se aos arquivos on-line dos principais jornais brasileiros, como Folha de S.Paulo, $O$ Estado de S. Paulo e O Globo.

No caso argentino, foram utilizados os dados do Programa de Estudios sobre las Elites e do Observatorio de las Elites Argentinas, sediados no Instituto de Altos Estudios Sociales da Universidad Nacional de San Martín. As fontes consultadas para conformar essas bases foram jornais de circulação nacional, imprensa especializada, documentos pessoais e currículos de ex-ministros, memórias, biografias, entrevistas em profundidade e estudos especializados sobre os diversos períodos históricos cobertos por nossa pesquisa. Na Argentina, o guia Who's who parou de ser publicado em meados do século XX e, atualmente, só existe um equivalente desse tipo para parlamentares, de modo que a reconstrução das trajetórias de outro tipo de pessoal político, como ministros, requer triangulação de fontes e dupla verificação das informaçôes.

Estudamos todos os casos de sobrevivência ou saída do gabinete em todos os ministérios da Argentina e do Brasil entre 1983 e 2016 . Utilizamos como critério de recorte temporal o período de redemocratização para o início do estudo. A coleta de informaçóes englobou, no caso da Argentina, o período de 1983 a 2015 e, no caso do Brasil, de 1985 a 2016. Para início da coleta, escolhemos os anos em que se encerraram as ditaduras militares nos dois países; os anos finais representam o fim do segundo mandato de Cristina Fernández de Kirchner, na Argentina, e a interrupção por impedimento do segundo mandato de Dilma Rousseff, no Brasil. Como critério de seleção dos nomes que figurariam em nossa lista de ministros, elegemos aqueles titulares que permaneceram em seus cargos por um tempo superior a noventa dias, reduzindo o impacto que causaria a presença de interinos na análise do turnover ministerial. Essa decisão permitiu eliminar de nossa base de dados os valores extremos que distorceriam os resultados. Por exemplo, durante as quatro presidências que ocorreram a partir da crise de 2001 na Argentina, muitos ministros duraram apenas um dia em seus postos e outros nem sequer chegaram a assumir formalmente seus cargos, apesar de ocuparem a função.

O número de ministérios na Argentina foi historicamente bem menor que no Brasil, em função do artigo 87 da Constituição de 1853, que determinava a existência de cinco portfólios apenas: Ministério do Interior, Ministério das Relações Exteriores, Ministério da Fazenda, Ministério da Justiça, Culto e Instrução Pública e Ministério da Guerra e da Marinha. Quarenta e três anos depois, em 1898, uma reforma constitucional autorizou a criação do Ministério da Agricultura e a separação dos ministérios da Guerra e da Marinha, elevando o número de pastas para oito. Seriam necessários mais 45 anos para que novas mudanças substanciais na estrutura do gabinete presidencial fossem produzidas pelo governo militar de 1943 e após a eleição de Juan Domingo Perón em 1946 (Campione, 2007; Berrotarán, 2012; Stawski, 2012). Posteriormente, com a reforma constitucional de 1994, foram retirados 
os limites legais para a criação de ministérios, cujo número passou a aumentar ou a diminuir ao sabor da dinâmica política. Assim, depois de 1994, os diferentes presidentes criaram diversas pastas, a princípio de forma tímida e em seguida com mais ímpeto, até culminar em 25 ministérios na presidência de C. Kirchner, em dezembro de 2015. Contudo, muitos desses ministérios não tinham sua continuidade garantida, e sempre nas sucessóes de presidentes algumas pastas eram suprimidas e outras novas eram criadas. A única exceção é a Jefatura de Gabinete de Ministros, criada também na reforma constitucional de 1994, que é uma pasta fixa do gabinete nacional. Em setembro de 2018, logo após uma crise econômica que produziu inflação, desvalorização da moeda, corrida cambial e acordo com o Fundo Monetário Internacional (FMI), o governo de Mauricio Macri reduziu o número de ministérios para apenas onze como um sinal de política de austeridade fiscal. ${ }^{11}$

Em nossa base de dados, os titulares de cada uma das pastas ministeriais dos dois países foram registrados em função do número de mandatos exercidos. Isso significa que um mesmo indivíduo pode aparecer mais de uma vez em nossos registros se ocupou a mesma pasta em governos diferentes, pastas distintas em governos diferentes ou pastas diferentes num mesmo governo. Assim, a unidade de análise é o mandato ministerial.

A Tabela 1 resume o universo estudado. Os dois países somam 699 casos, mas $75 \%$ dos ministros do banco de dados pertencem ao Brasil e 25\% à Argentina. Esse dado seria um indicativo da necessidade de o presidencialismo brasileiro acomodar um número muito maior de aliados de partidos diversos no gabinete.

Essa diferença na quantidade de casos não é um problema na medida em que analisamos e comparamos não amostras representativas, mas a população de ministros argentinos e brasileiros no período indicado.

\section{O turnover ministerial no Brasil e na Argentina: estabilidade e chances de sobrevivência em dois presidencialismos}

Brasil e Argentina, apesar de serem muito diferentes quanto ao número de ministérios e quanto ao número de ministros e de mandatos ministeriais (Tabela 1), pouco se diferenciam quanto ao tempo de permanência dos ministros nos seus cargos. Dados sumarizados da estatística descritiva sobre a troca ministerial na Argentina e no Brasil podem ser vistos na Tabela 2.

A média de permanência no posto é próxima para os dois países, mas levemente maior para a Argentina (23 meses, contra 20 do Brasil). Os valores da mediana do tempo de um ministro no gabinete também são semelhantes para a Argentina (18 meses) e para o Brasil (15 meses). A mediana, nesse caso, é uma medida mais precisa, em especial quando se considera a presença de um outlier na Argentina, um ministro que permaneceu na função por 65 meses.

Tabela 1

Número de Ministros por Presidente e por País e Períodos de Mandato Presidencial, Argentina (1983-2015) e Brasil (1985-2016)*

\begin{tabular}{lcclcc}
\hline \multicolumn{1}{c}{ Argentina } & Meses & Ministros & \multicolumn{1}{c}{ Brasil } & Meses & Ministros \\
\hline Raúl Alfonsín (1983-1989) & 67 & 24 & José Sarney (1985-1990) & 60 & 78 \\
Carlos Menem I (1989-1995) & 72 & 30 & Fernando Collor de Mello (1990-1992) & 31 & 45 \\
Carlos Menem II (1995-1999) & 53 & 18 & Itamar Franco (1992-1994) & 24 & 55 \\
Fernando de la Rúa (1999-2001) & 24 & 21 & Fernando Henrique Cardoso I (1995-1998) & 48 & 50 \\
Eduardo Duhalde (2002-2003) & 17 & 14 & Fernando Henrique Cardoso II (1999-2002) & 48 & 56 \\
Néstor Kirchner (2003-2007) & 54 & 19 & Luiz Inácio Lula da Silva I (2003-2006) & 48 & 65 \\
Cristina F. de Kirchner I (2007-2011) & 48 & 25 & Luiz Inácio Lula da Silva II (2007-2010) & 48 & 58 \\
Cristina F. de Kirchner II (2011-2015) & 48 & 25 & Dilma Rousseff I (2011-2014) & 48 & 73 \\
& & & Dilma Rousseff II (2015-2016) & 16 & 43 \\
TOTAL & & 176 & TOTAL & 523 \\
\hline
\end{tabular}

* Para o caso brasileiro, foram incluídos todos os Ministérios Extraordinários, todas as Secretarias Especiais e o próprio Banco Central, cujo titular tinha status de ministro. Fonte: Codato, Perissinotto e Gené, 2020. 
Tabela 2

Tempo de Permanência Ministerial em Meses, Argentina (1983-2015) e Brasil (1985-2016)

\begin{tabular}{lccccccc}
\hline \multicolumn{1}{c}{ País } & $\begin{array}{c}\text { Número de } \\
\text { ministros }\end{array}$ & Média & Mediana & $\begin{array}{c}\text { Desvio } \\
\text { padráo }\end{array}$ & Assimetria & Mínimo & Máximo \\
\hline Argentina & 176 & 23,21 & 17,61 & 15,093 & 0,814 & 4 & 65 \\
Brasil & 523 & 20,32 & 15,05 & 14,665 & 0,900 & 3 & 60 \\
Total & 699 & 21,05 & 16,23 & 14,817 & 0,872 & 3 & 65 \\
\hline
\end{tabular}

Fonte: Codato, Perissinotto e Gené, 2020.

A medida de assimetria indica o grau de distorção da distribuição em relação a uma distribuição simétrica. Os valores para os dois países são consideravelmente altos, o que indica uma distribuição muito assimétrica dos dados (tempo no gabinete), com os valores se concentrando nos períodos iniciais de governo (basicamente no primeiro ano e meio de mandato), mostrando haver mais saídas - e, portanto, maior instabilidade - na fase inicial dos governos dos dois países.

No caso do Brasil, a quantidade de ministérios é muito maior. Embora, como dissemos na nota 4, não exista uma relação causal entre número de ministérios e número efetivo de partidos no Parlamento, é lícito supor que o aumento constante deste último no caso brasileiro contribua para aumentar o tamanho das coalizóes presidenciais e, por extensão, o número de pastas ministeriais para acomodar os aliados. Alguns governos podem até resistir a essa pressão, mas tendem a pagar um alto preço político por isso (como foi o caso paradigmático de Fernando Collor de Mello). $\mathrm{Na}$ Argentina, o presidencialismo dispensa esse tipo de coalizão (embora não dispense coalizóes políticas de outro tipo). Ademais, o número de ministérios sofreu, como vimos, constrangimentos constitucionais e, por isso, as mudanças são bem menos frequentes. Apesar disso, os dados referentes à estabilidade ministerial não expressam diferenças significativas entre os dois casos. Essa evidência é confirmada quando vemos as funções de sobrevivência nos dois países (Gráfico 1).

$\mathrm{Na}$ análise de sobrevivência, a variável dependente é sempre o tempo até a ocorrência de determinado evento - já na análise estatística clássica, a variável dependente é a ocorrência ou não de determinado evento. No eixo Y está representado o percentual de ministros "vivos" (ou livres do desfecho: saída do gabinete) em funçáo do tempo de entrada no estudo, o eixo X, em um gráfico de coordenadas. A função de sobrevivência no gabinete é representada pelas curvas do estimador Kaplan-Meier e caracterizada como uma escada com degraus nos tempos observados de ocorrência do evento de interesse ("saída do ministro do governo"). Degraus nessa escada representam a ocorrência do evento, e o tamanho do degrau é proporcional ao número de eventos ocorridos no tempo $t$, definido aqui como o número de meses de permanência do titular da pasta ministerial. $O$ teste permite avaliar quais as chances de um indivíduo sofrer um evento específico, no nosso caso, sair do cargo de ministro antes do término do mandato do presidente. ${ }^{12}$ Para tanto, é preciso dividir o universo de indivíduos entre aqueles que sofreram o evento, isto é, a saída antes do fim do mandato do presidente, e aqueles que não o sofreram, isto é, que permaneceram no posto até o fim do mandato presidencial. Estes últimos compóem os chamados "casos censurados". Entre os dados há 83 casos censurados na Argentina e 239 casos censurados no Brasil.

O Gráfico 1, tomando todos os ministérios para o período analisado, não revela qualquer diferença significativa nas duas curvas de sobrevivência. Quando comparamos Brasil e Argentina, as linhas são muito similares, quase se sobrepondo uma à outra. Por essa razão, nenhum dos testes de significância estatística (Log rank, Breslow e Tarone-Ware) se revelou significativo ( $p$ valor $>0,005)$.

Os valores de Log rank (Mantel-Cox), que dão peso maior ao início e ao meio do segmento, mostram que não existe diferença entre os países; Breslow dá peso maior para o início do segmento e indica que não existe diferença entre os grupos; e Tarone-Ware, que dá maior peso para o final do segmento, indica que também não existe diferença significativa entre os grupos em ambos os regimes presidencialistas. Assim, 


\section{Gráfico 1}

Teste de Sobrevivência Kaplan-Meier para Argentina (1983-2015) e Brasil (1985-2016)

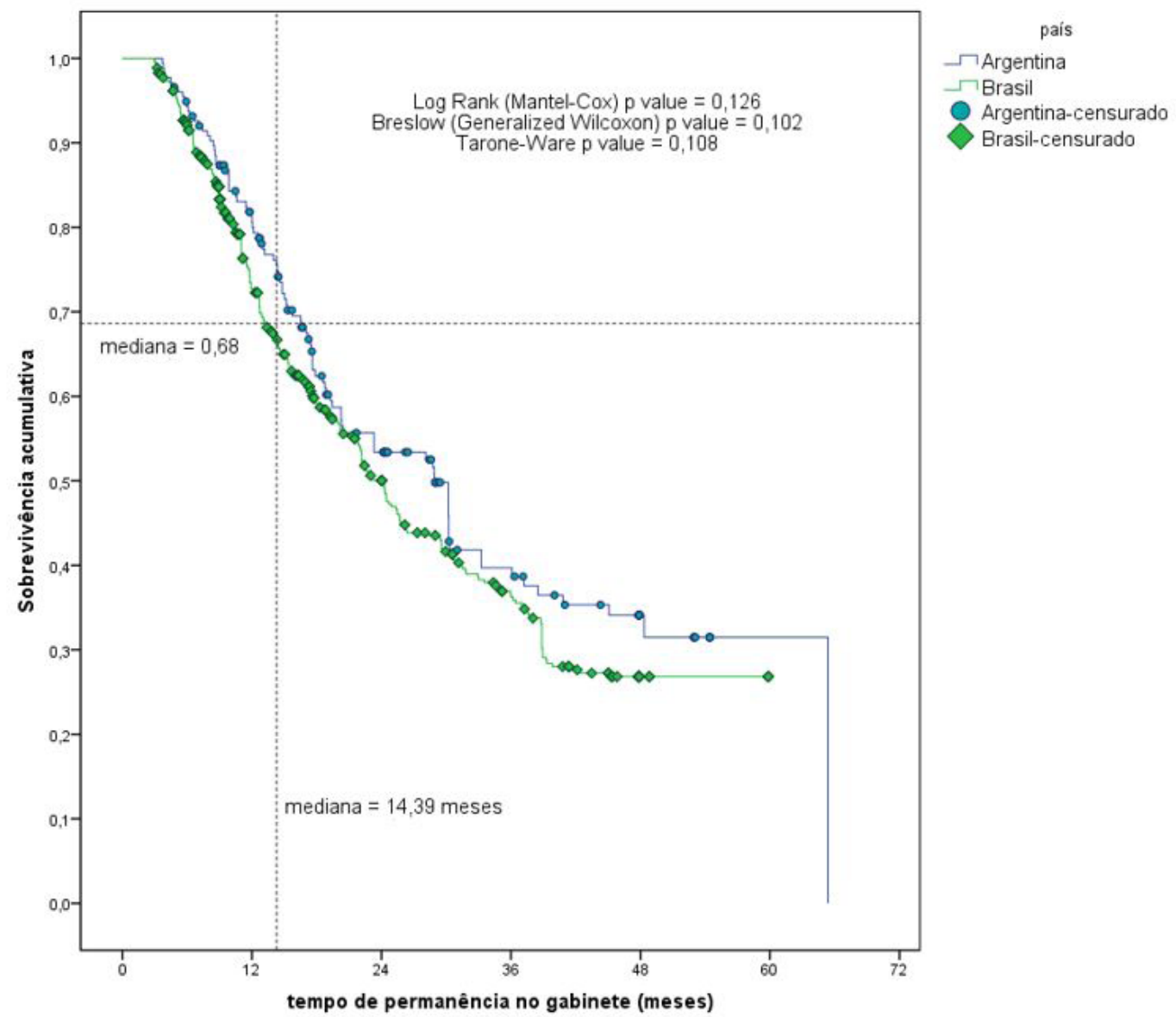

Argentina: Número total de casos: 176; Número de eventos (saídas): 93 (52,8\%). Brasil: Número total de casos: 523; Número de eventos (saídas): 284 (54,3\%). Fonte: Codato, Perissinotto e Gené, 2020.

o presidencialismo de coalizão e o presidencialismo de partido único não se diferenciam com relação às funçôes de sobrevivência.

Esse é um resultado contraintuitivo. Como vimos na revisão bibliográfica, já há bastante tempo a literatura estabelece forte relação entre a durabilidade dos gabinetes ministeriais no tempo e a quantidade de partidos envolvidos na sua formação. Assim, seria esperado que as chances de sobrevivência dos ministros argentinos fossem significativamente diferentes em relação às dos ministros no Brasil, o que não ocorre. Desse modo, a nossa H1, de que diferentes regimes de governo (presidencialismo de coalizão e presidencialismo de partido único) produziram diferentes regimes de sobrevivência ministerial, não foi confirmada.

\section{O turnover ministerial no Brasil e na Argentina por governos: o contexto conta}

Os dados revelaram que diferenças institucionais existentes entre os dois presidencialismos não explicam o (baixo) tempo de sobrevivência dos ministros brasileiros e argentinos nos seus cargos. Assim, para tentar explicar a dinâmica do turnover ministerial no Brasil e na Argentina seria melhor olhar para cada governo de cada país separadamente.

Apresentamos, a seguir, um indicador de instabilidade ministerial. O indicador, proposto por Santos, compara os presidentes entre si levando em conta o tempo que ficaram no cargo, mas compensando "a diferença de tempo nos respectivos mandatos constitucionais efetivamente cumpridos" (Santos, 1986, pp. 118-119). 
Como os diferentes governos têm duração muito distinta (ver Tabela 1), os dados sobre o tempo de permanência dos ministros no gabinete deveriam ser lidos com base em suas dinâmicas políticas próprias. ${ }^{13}$

$\mathrm{O}$ coeficiente do indicador de instabilidade ministerial varia de 0 a 1 . Quanto maior o valor do coeficiente, maior o nível de instabilidade apresentado pelo governo (Santos, 1986, p. 122). Seguindo a fórmula proposta, calculamos primeiro a estabilidade ministerial de dado governo a partir de quatro variáveis: (1) tempo de permanência efetiva do presidente no cargo; (2) tempo de permanência máximo segundo a Constituição; (3) número de ministros de Estado nomeados pelo chefe de governo; (4) número de ministérios de determinado governo. $\mathrm{O}$ coeficiente de estabilidade do gabinete é obtido da seguinte forma: multiplica-se o valor da variável 1 pelo valor da variável 4 e divide-se o resultado pelo número de ministros que entraram em funçăo (variável 3). $\mathrm{O}$ valor obtido é a duração média dos mandatos ministeriais (variável 5). ${ }^{14}$ Esse valor (variável 5) é então dividido pelo tempo de permanência máximo do presidente segundo a Constituição em vigor ${ }^{15}$ (variável 2), para se obter o coeficiente de estabilidade ministerial comparada $\{(1 \times 4) / 3=5\} ;\{5 / 2=$ coeficiente $\}$. Esses cálculos são feitos por Santos para medir o desvio em relação a uma hipotética "estabilidade perfeita", na qual o número de ministros corresponderia ao número de ministérios e o tempo médio de exercício do cargo seria igual ao tempo total de duração do mandato constitucional, isto é, um ministro por ministério durante o tempo do mandato presidencial como definido na Constituição. Como um governo pode ter uma estabilidade ministerial perfeita e, assim mesmo, ser derrubado antes do término de seu mandato, o tempo constitucional deve ser levado em consideração para um cálculo preciso da estabilidade comparada entre governos que duraram todo o mandato constitucional e governos que terminaram antes (cf. Santos, 1986, pp. 118-121). ${ }^{16}$

Para que o valor fique mais intuitivo, subtraímos de 1 o resultado (1-estabilidade ministerial comparada), de modo que, quanto mais alto o valor, maior a instabilidade ministerial. Os cálculos do indicador são apresentados nos Gráficos 2 e 3.

A linha de tendência do Gráfico 3 é relativamente estável para o Brasil (exceto no governo Rousseff II) e claramente descendente para a Argentina (Gráfico 2). $\mathrm{Na}$ Argentina, a instabilidade era alta $(0,69$ no governo de Raúl Alfonsín, maior mesmo que no problemático governo de José Sarney, com 0,62) e caiu para o menor nível de toda a série em C. Kirchner II $(0,32)$, menos da metade. No Brasil, a instabilidade, que era média $(0,52)$, subiu bruscamente ao final da série histórica $(0,75)$, com a interrupção do segundo mandato de Rousseff. Quando se comparam os nove governos brasileiros do período analisado, os valores do coeficiente de Santos não se distanciam muito

\section{Gráfico 2}

\section{Coeficiente do Indicador de Instabilidade Governamental por Presidentes, Argentina (1983-2015)}

coeficiente de instabilidade: Argentina

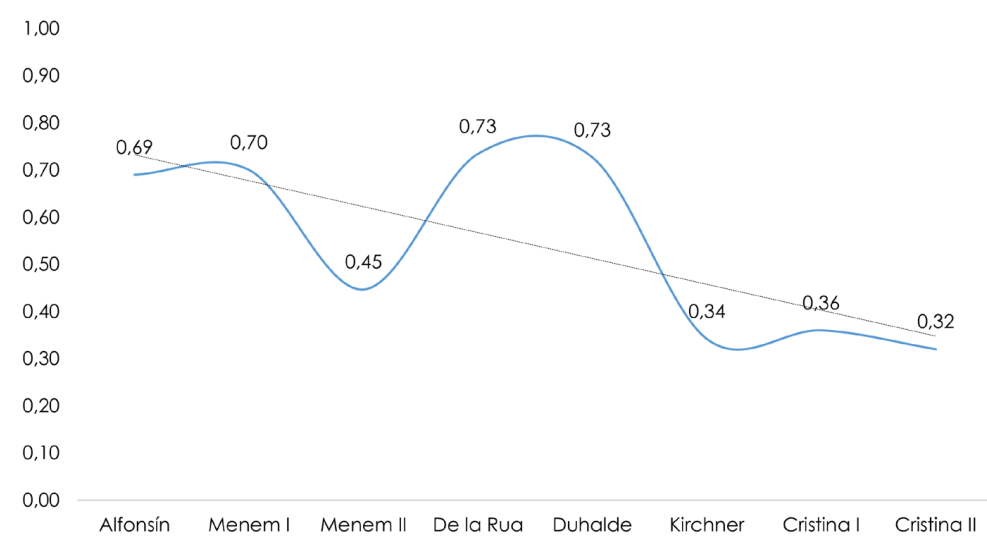

Média do coeficiente para o período considerado: 0,54. Fonte: Codato, Perissinotto e Gené, 2020. 


\section{Gráfico 3 \\ Coeficiente do Indicador de Instabilidade Governamental por Presidentes, Brasil (1985-2016)}

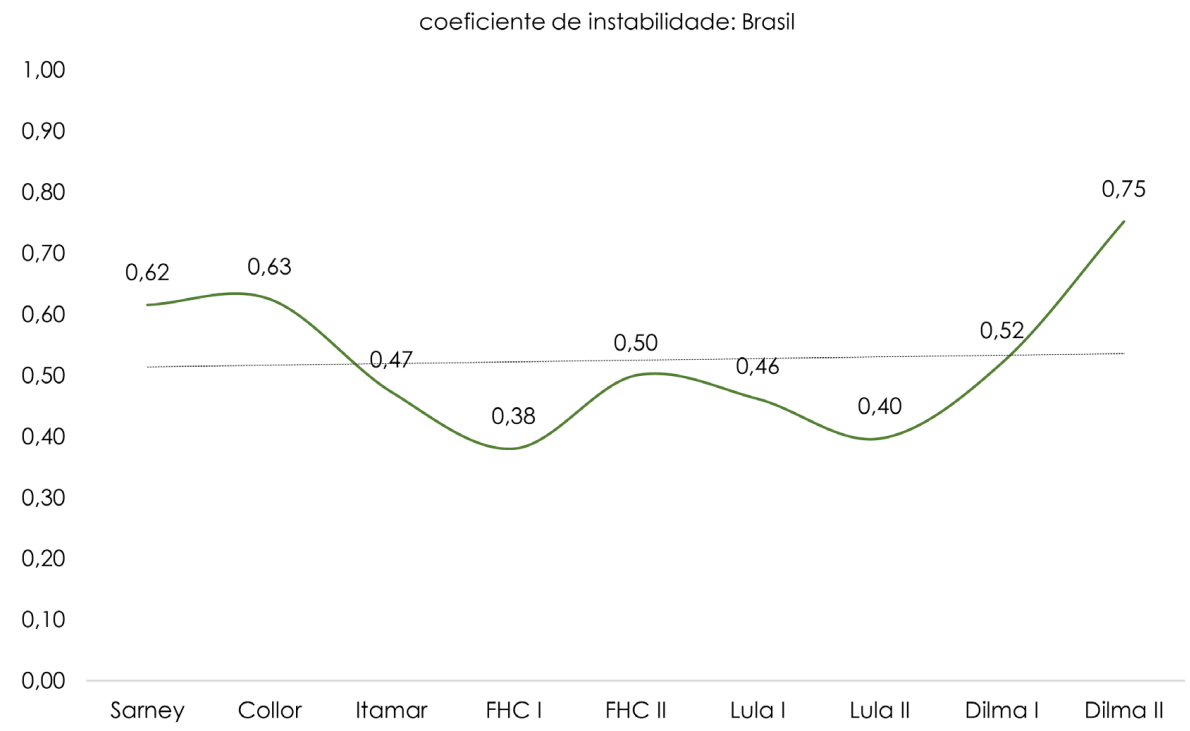

Média do coeficiente para o período considerado: 0,52. Fonte: Codato, Perissinotto e Gené, 2020.

entre si, exceto nas duas pontas do Gráfico 3. Durante todo o intervalo de "estabilidade democrática", entre Itamar Franco e o primeiro governo de Rousseff, o coeficiente de instabilidade fica baixo ou é igual à média. $\mathrm{O}$ caso argentino (Gráfico 2 ) apresenta maior variabilidade, chegando ao menor valor no segundo mandato de C. Kirchner (0,32), uma estabilidade dos gabinetes desconhecida no Brasil. Nossa interpretação é que o trajeto das duas linhas tem menos a ver com a natureza dos presidencialismos e mais com as sucessivas crises econômicas e políticas dos dois países nessas décadas. Por essa medida, gabinetes na Argentina são, em média, ligeiramente mais instáveis que no Brasil $(0,54$ contra 0,52$)$. Mas as médias tomadas isoladamente dizem muito pouco e não diferenciam os dois sistemas políticos. As oscilações, para cima e para baixo, são um registro objetivo das dinâmicas políticas de Argentina e Brasil. Todavia, as curvas parecem responder mais às diferentes conjunturas políticas e aos desafios típicos de cada presidente isoladamente do que à natureza dos governos (se de coalizão ou não).

\section{A dinâmica política na Argentina}

O governo de Alfonsín é o que conduziu a transição política da ditadura militar à democracia e, enquanto tal, trouxe consigo a marca da instabilidade inerente à sua condição. Nesse caso, além da crise econômica do período, a transição política e o enfrentamento de questóes referentes à violência do regime deram tons dramáticos ao governo da Unión Cívica Radical (UCR), contando inclusive com rebeliōes militares (os carapintadas) que, em reação às intenções do governo de levar adiante os processos contra autoridades envolvidas na repressão, organizaram tentativas fracassadas de golpe de Estado (Persello, 2007; De Riz e Smulovitz, 1991). Essa situação ajuda a explicar por que, no primeiro ano do seu governo, quase $20 \%$ do gabinete ministerial de Alfonsín foi alterado ${ }^{17}$ e esse governo atingiu um alto coeficiente de instabilidade ministerial, se comparado com os demais.

A instabilidade foi mantida nesse patamar durante o primeiro governo de Carlos Menem, que, no primeiro ano de seu mandato, também mudou algo em torno de $20 \%$ do seu gabinete presidencial e atingiu o mesmo patamar de Alfonsín no coeficiente de instabilidade. Isso se explica pelo fato de Menem ter enfrentado problemas significativos já no início de seu governo. Tendo assumido em julho de 1989, 
conviveu com a hiperinflação até 1991, visto que sua guinada liberal, com a reforma do Estado e a bateria de medidas pró-mercado, não logrou oferecer resultados perante a crise. Foi a instauração da convertibilidade entre a moeda argentina (o peso) e o dólar norte-americano que selou finalmente, por alguns anos, a estabilidade tão valorizada nessa década de governo (Heredia, 2015; Pucciarelli, 2011; Torre, 1999; Sigal e Kessler, 1997).

O segundo governo de Menem se iniciou mantendo o ritmo de mudança, mas alterou a sua dinâmica a partir do seu primeiro ano de governo. É provável que isso seja explicado pela estabilidade econômica conquistada a partir da implementação da paridade cambial entre o peso e o dólar (o famoso Plano Cavallo), que permitiu reduzir a inflação a praticamente zero no início de 1991. No entanto, a rigidez da paridade cambial, combinada com as crises econômicas externas, gerou dificuldades econômicas cada vez mais graves, tornando insustentável a continuidade daquela política. O segundo mandato de Menem começa a conviver com a crise, presenciando a redução do crescimento econômico e o drástico aumento do desemprego, que atinge a faixa dos $18 \%$.

Temos então o período de maior turbulência econômica e política da história argentina posterior à redemocratização, marcando dramaticamente o governo do presidente Fernando de la Rúa. O governo do novo presidente era tão instável que, no período de um ano, teve de renovar quase $50 \%$ do seu gabinete, e em quinze meses essa renovação chegava a $80 \%$. Empossado em dezembro de 1999, De la Rúa, eleito pela Alianza entre a UCR e a Frente País Solidario (Frepaso), ficou no cargo por apenas dois anos, quando renunciou depois de enfrentar uma série de revoltas e protestos contra sua política econômica (em especial, o famoso corralito). O Congresso indicou Ramón Puerta, presidente provisório do Senado e o primeiro nome na linha sucessória. No entanto, suas aspiraçóes presidenciais lhe renderam a oposição das mais importantes províncias do país, como Buenos Aires, Santa Fé e Córdoba (Novaro, 2006). Foi então sucedido por Adolfo Rodríguez Saá, governador da província de San Luis, que deveria ficar no cargo até que novas eleições presidenciais fossem convocadas. Saá ficou por apenas oito dias, tendo renunciado também em função dos protestos contra as medidas de seu governo e da falta de apoio parlamentar e dos demais governadores de seu partido. Novamente reunido, o Congresso decidiu pela nomeação de Eduardo Camaño, presidente da Câmara de Deputados, que durou apenas três dias no cargo. ${ }^{18}$ Finalmente, a Assembleia Legislativa nomeou aquele que conseguiu reunir o apoio da maioria, o então governador de Buenos Aires, Eduardo Duhalde, que foi mantido no cargo até abril de 2003. Ainda que a intenção fosse que Duhalde completasse o mandato de De la Rúa, em dezembro de 2003, teve de adiar as eleiçóes em razão da forte repressão contra um protesto, que resultou na morte de duas pessoas. Todo esse processo foi permeado, como não poderia deixar de ser, por entradas e saídas muito rápidas de ministros, e, no caso de De la Rúa, com a renúncia coletiva de seu gabinete em dezembro de 2001. Essa instabilidade continuou no governo de Duhalde, que renovou $20 \%$ do seu gabinete nos primeiros cinco meses do seu também curto governo.

Ao contrário, os governos do kirchnerismo revelam um aumento da estabilidade ministerial em comparação com os demais governos argentinos no período analisado. Apesar da fragilidade de ter chegado ao Poder Executivo da nação com a menor quantidade de votos da história argentina (apenas 22\%), em função da recusa de Menem em disputar o segundo turno das eleiçóes presidenciais, o governo de Néstor Kirchner construiu uma liderança particularmente poderosa. Desde sua chegada à Presidência, mostrou-se ao mesmo tempo proativo e receptivo perante as demandas dos cidadáos, renovando a Corte Suprema, encarando uma política de direitos humanos diametralmente oposta à de seus predecessores imediatos e renegociando a suspensão da dívida. Os indicadores sociais e econômicos foram positivos durante o seu mandato, que terminou com um recorde de apoio a sua gestáo (Pucciarelli e Castellani, 2017; Levitsky e Murillo, 2008; Rinesi e Vommaro, 2007). Os dois governos de sua sucessora, C. Kirchner, a despeito dos intensos conflitos com setores empresariais do campo e com as grandes empresas de comunicação do país, conseguiram promover crescimento econômico e políticas de inclusão social. Nesse contexto, o auge da estabilidade 
ministerial ocorreu no seu segundo governo, que conseguiu manter, por todo o seu mandato, intactos, quase $60 \%$ do seu gabinete ministerial. $\mathrm{O}$ segundo governo de C. Kirchner parece representar assim a consolidação de um processo de maior estabilização ministerial que começou com o governo de seu marido.

No caso brasileiro a situação se repete, isto é, somente analisando governo a governo conseguimos entender os números sobre a rotatividade ministerial.

\section{A dinâmica politica no Brasil}

São os governos de transição (Sarney) e de crise política (Collor e Rousseff) que apresentam os maiores coeficientes de instabilidade, como já vimos. São também governos que passam por forte crise econômica e inflacionária, no caso dos dois primeiros, e queda do produto interno bruto (PIB), no caso do último. Collor e Rousseff são também governos assolados por denúncias de corrupção sistemática, que afetaram significativamente a imagem política dos dois presidentes. No caso dos dois, é possível ainda acrescentar à análise os traços de personalidade, que aumentavam as dificuldades no relacionamento com o Congresso Nacional. ${ }^{19}$ Sarney renovou quase $50 \%$ do seu ministério no prazo de um ano de governo e chegou ao final do seu mandato com $80 \%$ de renovação. Para Collor, esses percentuais são, respectivamente, algo ao redor de $30 \%$ e $80 \%$. Com Franco, governo que assume em decorrência do processo de impedimento de Collor, os doze primeiros meses são também de intensa renovação, atingindo o percentual de 50\% e se estabilizando mais ou menos nesse patamar até o seu final.

O primeiro governo de Fernando Henrique Cardoso (FHC), quando se estabiliza definitivamente a economia brasileira no seu aspecto inflacionário e se elimina definitivamente o mais grave da crise política vivida nos anos anteriores, consegue manter um baixo índice de renovação ministerial nos doze primeiros meses, garantindo a sobrevivência de quase $75 \%$ de seus ministros, embora termine o seu mandato tendo renovado $60 \%$ do seu ministério. O segundo governo de FHC, que, a despeito do controle da inflação, convive com crise de crescimento e forte desemprego, entra o primeiro ano já com $30 \%$ de renovaçấo do gabinete e termina o governo com troca de $70 \%$ dos ministros. O primeiro governo de Luiz Inácio Lula da Silva, por sua vez, apresenta a taxa mais baixa de renovação durante os primeiros doze meses do governo. Isso é certamente reflexo da tentativa de o novo governo reservar a maior parte das pastas ministeriais ao seu partido, o Partido dos Trabalhadores (PT). Essa foi sabidamente uma das razóes para um crescente ruído na relação entre o governo e sua base aliada, ruído esse que foi fortemente alimentado pela crise do Mensaláo. ${ }^{20} \mathrm{~A}$ combinação desses dois problemas explicaria a alta taxa de renovaçáo no final do governo, atingindo o patamar dos governos de crise, como Sarney e Collor. O segundo governo de Lula, já convencido da necessidade de distribuir adequadamente as pastas pelos partidos aliados, atinge renovaçáo de $10 \%$ em um ano e de $50 \%$ no final do governo, talvez o mais estável governo da história brasileira depois da redemocratização.

Os dois governos de Rousseff, porém, representam o fim do idílio da governabilidade. Seu primeiro governo inicia com uma taxa de renovação de $25 \%$ em um ano, terminando com uma renovação total de $70 \%$. O segundo governo, operando em meio aos rescaldos das grandes manifestaçóes de 2013, ao avanço das investigaçóes da Operação Lava-Jato, às amplas manifestaçôes de rua pelo impeachment da presidente e sob forte crise econômica, apresenta uma taxa de renovaçáo nos primeiros doze meses impressionantemente alta, de $60 \%$, tendo renovado o seu gabinete em $70 \%$ por ocasião do seu afastamento da Presidência da República.

Percebe-se, portanto, que a instabilidade política, pensada em termos de turnover ministerial, não pode ser vista aqui como resultado exclusivo da dinâmica institucional dos dois presidencialismos. Os coeficientes de instabilidade dos dois países apresentam valores levemente diferentes quando comparados entre si e bastante díspares quando os governos de cada país são usados como unidade de comparação. Desse modo, se náo levamos em conta o contexto político e econômico de cada governo, não conseguimos explicar a instabilidade ministerial nesses dois sistemas políticos. 


\section{Razóes de saída no Brasil e na Argentina: novamente o contexto}

Seria o contexto econômico e político também importante para entender as razóes de saída dos ministros?

A fim de analisar essa questáo, codificamos as múltiplas razóes de saída em seis categorias: (i) desempenho (quando o ministro sai por crítica a sua performance à frente da pasta), (ii) eleiçóes (quando sai para disputar eleiçóes), (iii) embate (por conflitos internos ao gabinete presidencial, com outros ministros ou com o próprio Presidente), (iv) escândalo (quando sai por escândalos públicos, sobretudo de corrupção), (v) reforma ministerial (saída por mudanças no gabinete e trocas de uma pasta ministerial por outra pelo mesmo ministro, em função de recomposiçóes políticas), e (vi) queda de governo (saída por impedimento do presidente da República ou queda em função de crise política generalizada). Foram excluídas todas as saídas de ministros de governo em fim de mandato (quando o ministro deixa a pasta junto com o presidente). Foram deixados de fora dos cálculos demissóes por razóes pessoais e por doença e falecimentos.

O Gráfico 4 mostra, por meio de resíduos padronizados ajustados, uma clara associação entre razões de saída e os países estudados. Quanto mais os resíduos são inferiores a $-1,96$ ou superiores a 1,96, maior a associação (negativa ou positiva) entre as variáveis. ${ }^{21}$

Os dados revelam algumas diferenças e algumas semelhanças importantes. Duas razóes são as mais discrepantes: saída do titular do ministério para disputar eleiçôes, bem mais presente no Brasil (resíduos de $3,3)$ que na Argentina $(-3,3)$, e mau desempenho à frente da pasta, bem mais presente na Argentina $(5,9)$ que no Brasil $(-5,9)$. O achado refuta nossa $\mathrm{H} 2$, que sustentava que reformas de gabinete, para reacomodar na coalizão partidos aliados, poderia ser a principal razão de saída no caso brasileiro.

\section{Gráfico 4}

\section{Razóes de Saída do Gabinete Ministerial por País em Resíduos Padronizados Ajustados}

arasil argentina

queda de governo

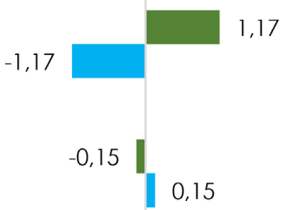

reforma

escândalo

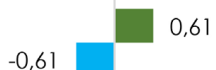

escândalo

$-0,61$

embate

$-0,20$
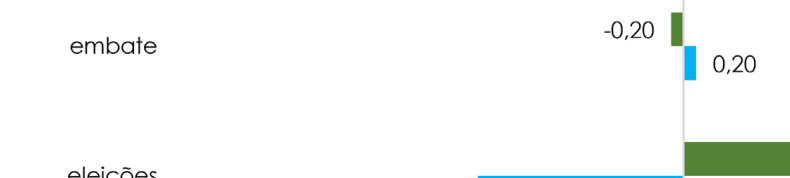

eleições

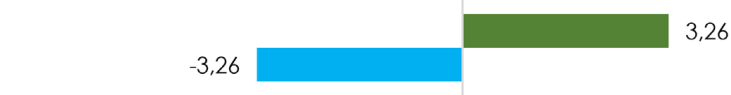

desempenho

$-5,94$

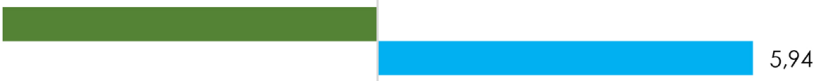

$-8,00$

$-6,00$

$-4,00 \quad-2,00$

0,00

2,00

4,00

6,00

8,00

Número de casos: Argentina (99); Brasil (295). Qui-quadrado 42,919 | df $5 \mid p$ value 0,000. Fonte: Codato, Perissinotto e Gené, 2020. 
O Brasil passou, durante o período analisado, por dois processos de impeachment (1992 e 2016), com a queda de boa parte do gabinete. Na Argentina também tivemos a saída de De la Rúa (queda de governo), o que explica a semelhança dos percentuais referentes a essa razão de saída (9,1\% para Argentina, $13,6 \%$ para o Brasil).

Chama a atençáo também que, apesar de ser um presidencialismo de partido único, a Argentina demite seus ministros por reforma ministerial $(32,3 \%$ do total de dispensas) tanto quanto o Brasil (31,5\%). Esse dado, aparentemente contraintuitivo, na verdade não o é. A literatura sobre formação de gabinete na Argentina tem mostrado que se, por um lado, o governo é de partido único, isso, por outro, não exime o presidente de atender às diferentes facçôes dentro do próprio partido, o que, não raro, é feito pela via da reforma ministerial (De Luca, 2011). Nesse sentido, reformas ministeriais podem ser tão frequentes no presidencialismo de coalizáo quanto no de partido único. $\mathrm{O}$ fato é que o partido do presidente não é uma organização homogênea e monolítica, mas perpassada por diversas divisōes internas. Suas facçôes condicionam o apoio ao presidente à sua presença no gabinete. Além disso, na Argentina, a troca de ministros em bloco (isto é, de mais de um ou dois ministros ao mesmo tempo) ocorre usualmente para "relançar" o governo frente a algum contexto crítico (derrota eleitoral, crise econômica, escândalos etc.). Longe de buscar um novo equilíbrio no interior $\mathrm{da}$ coalizão, essas reconfiguraçôes do gabinete almejam melhorar a imagem do governo, mostrar uma atitude proativa ante uma situação problemática e denotar capacidade de reaçáo. Ou seja, tanto o presidencialismo de coalizão como o de partido único promovem reformas ministeriais amplas, ainda que por razóes distintas. ${ }^{22}$

A Argentina dispensa seus ministros muito mais por razóes de desempenho $(22,2 \%$ do total de demissóes) que o Brasil (apenas 3,4\%), especialmente no caso do Ministério da Economia, que é, de longe, o mais visado de todo o gabinete. O Brasil, por sua vez, dispensa seus ministros por razóes eleitorais muito mais que a Argentina (18,6\% do total de demissóes contra apenas 5,1\%). No caso de embates internos entre membros da equipe de governo, os valores são muito semelhantes (18,3\% para o Brasil, 19,2\% para a Argentina). O mesmo se dá com escândalos: enquanto $14,6 \%$ dos ministros brasileiros deixam o gabinete por essa razão, na Argentina o número chega a $12,1 \%$.

Os gráficos 5 e 6 apresentam as razóes de demissão por governo e cada país. Os tipos de causas das saídas dos ministros na Argentina mostram uma importante variação por presidente. Nos governos que enfrentaram grandes crises, políticas ou econômicas, as mudanças ministeriais por desempenho foram majoritárias, exceto no caso de De la Rúa, em que predomina, como seria esperável, a queda do governo. Foi esse o caso do governo da transição para a democracia de Alfonsín (47\%), que teve de lidar com os julgamentos das juntas militares e terminou o mandato em meio a uma crise econômica com hiperinflação, e o de Duhalde (67\%), que precisou administrar o caos econômico, social e político depois da crise de 2001. As saídas por escândalo foram altamente significativas no segundo governo de Menem (50\%) e, em menor medida, no primeiro (18\%). A década de 1990 foi, na Argentina, abundante em escândalos políticos, com o consequente protagonismo do jornalismo de investigação e dos especialistas em corrupçáo. A desenvoltura do estilo menemista começou a gerar mais críticas na sociedade quando da piora dos indicadores sociais, o que tornou seu segundo período menos imune a esses escândalos e a seus efeitos na opinião pública.

Por sua vez, os conflitos internos entre membros da equipe de governo, com embates entre os próprios ministros e deles com o presidente, foram importantes durante toda a segunda presidência de Menem (38\%) e durante o kirchnerismo (38\%). O governo da Alianza foi o único até 2015 formado por uma coalizão formalmente constituída entre dois partidos (UCR e Frepaso). A relação entre ambos foi conflitiva desde o início, como também foi a articulação entre as distintas fraçóes internas da UCR, principalmente. Por isso, as lutas intestinas e a fragmentaçẫo do governo foram constantes entre 1999 e 2001, o que explica a presença significativa do "embate" como razão de saída de ministros (24\%) no governo de De la Rúa, perdendo apenas para "queda do governo" (43\%). ${ }^{23}$

As trocas ministeriais amplas, aqui categorizadas como "reformas" ministeriais, foram particularmente 
importantes nos governos de Alfonsín (47\%), na primeira presidência de Menem (45\%) e no segundo governo de C. Kirchner (63\%), entre outras coisas, para demonstrar iniciativa após derrotas em eleições de meio-termo. Cabe observar que a saída dos ministros para disputar eleiçôes é muito menos significativa que quaisquer outras nos diversos governos. A exceção nesse ponto é o governo de N. Kirchner, em que essa

\section{Gráfico 5}

Razóes de Saída do Gabinete Ministerial, Argentina (1983-2015)

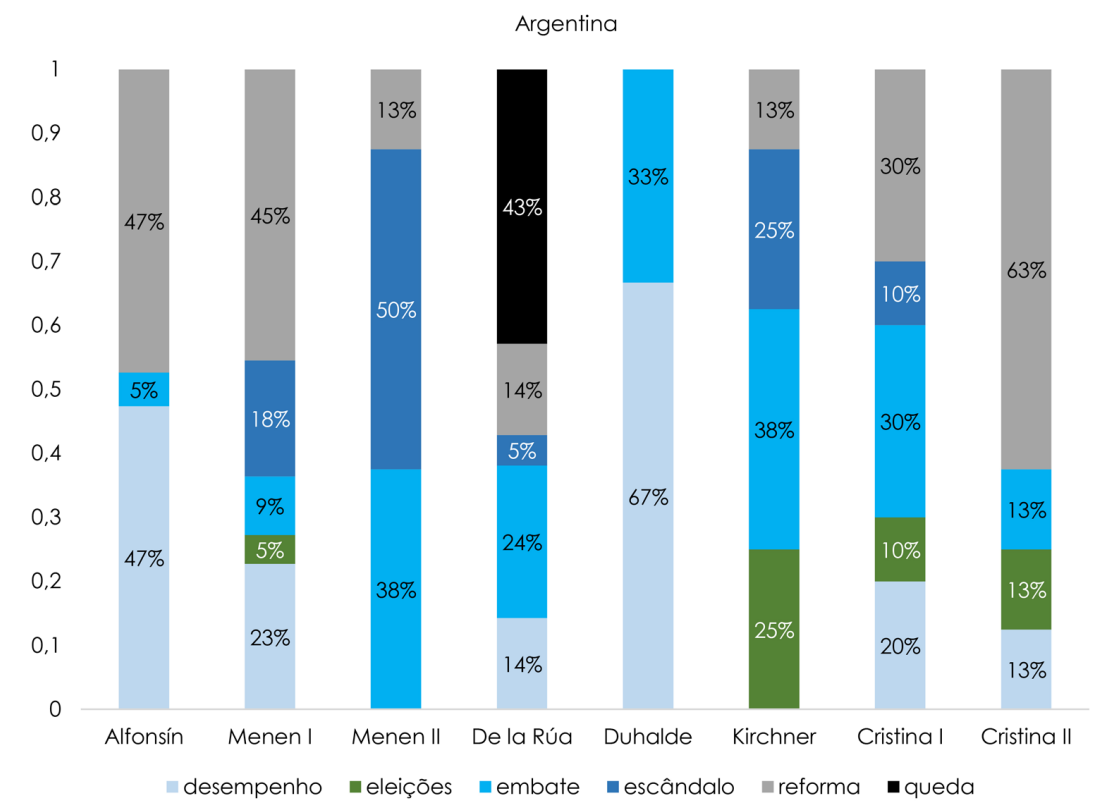

Qui-quadrado 89,145 | df 35 | p value 0,000. Casos válidos: 99. Fonte: Codato, Perissinotto e Gené, 2020.

\section{Gráfico 6}

Razóes de Saída do Gabinete Ministerial, Brasil (1985-2016)

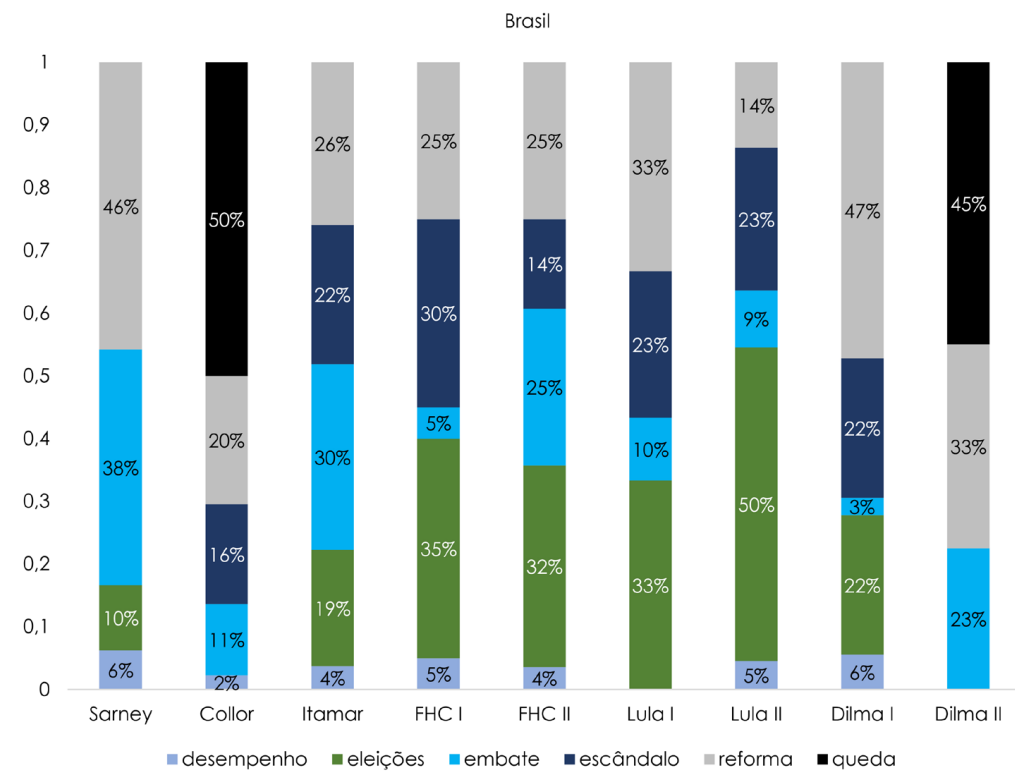

Qui-quadrado 198,332 | df 40 | p value 0,000. Casos válidos: 295. Fonte: Codato, Perissinotto e Gené, 2020. 
categoria atinge um quarto das razóes de saída. Isso se explica pela grande popularidade do seu governo e pelos resultados positivos atingidos em diversas áreas. Desse modo, para muitos dirigentes, a passagem pelo gabinete significou um trampolim para a carreira eleitoral ou uma maneira de reforçá-la.

No caso do Brasil (Gráfico 6), também convém separar os governos de crise e os governos estáveis. $\mathrm{O}$ governo de Sarney vivenciou período de forte crise econômica e política. Basta lembrar as tentativas fracassadas de estabilizaçáo monetária com os planos Cruzado, Bresser e Verão e o retorno de taxas inflacionárias altíssimas durante a sua administração. Do ponto de vista político, a gestão Sarney é homóloga ao governo Alfonsín, na Argentina, durante o período de transição da ditadura militar para a democracia, com o agravante da morte do presidente eleito pelo Colégio Eleitoral, Tancredo Neves, do qual Sarney era vice. Junte-se a isso o processo de formulação de uma nova Constituição (1988), que movimentou significativamente a sociedade civil, e as várias acusaçôes de corrupção em seu governo, entâo filiado ao Partido do Movimento Democrático Brasileiro (PMDB), que levaram à cisão dentro do partido e à formação do Partido da Social Democracia Brasileira (PSDB). Assim, não espanta que "embate" (38\%) e "reforma" (46\%) sejam as principais razóes de saída nesse governo.

Também não surpreende que no governo de Collor e no segundo governo de Rousseff "queda do governo" por impedimento apareça como a principal razão de saída dos ministros (50\% e 45\%, respectivamente). No caso de Rousseff, a razáo "reforma" é também muito importante, sendo a principal causa de demissóes no seu primeiro governo $(47 \%)$ e a segunda mais importante no governo posterior (33\%). Em Rousseff II, já em plena crise do impeachment, embate também aparece como uma razão de saída de peso (23\%).

É importante observar que somente nos dois governos de FHC e nos dois governos de Lula "sair do gabinete para disputar eleiçôes" aparece como razão principal da partida dos ministros dos respectivos portfólios. Essa é uma razão ausente nos governos impedidos (Collor e Rousseff II), porque o afastamento dos presidentes se deu antes das eleições municipais dos anos em que foram retirados. ${ }^{24}$ Parece-nos plausível dizer que o sucesso dos governos de FHC e Lula em equacionar os problemas mais urgentes de duas agendas dramáticas do Brasil, inflaçâo crônica e exclusão social, foi em grande parte responsável por seus ministros optarem por usar o capital político acumulado pelos presidentes para tentar a sorte na competição eleitoral.

\section{Conclusóes}

Este artigo se propôs a investigar comparativamente as chances de sobrevivência e as razóes de saída dos gabinetes ministeriais no Brasil e na Argentina, dois regimes presidencialistas, mas com lógicas políticas distintas, o primeiro, multipartidário, o segundo, unipartidário. Os dados apresentados autorizam formular duas conclusóes.

Brasil e Argentina não se diferenciam quanto às chances de sobrevivência dos ministros no cargo. Podemos dizer que o turnover ministerial, entendido como evidência do grau de estabilidade ou instabilidade dos governos, é similar nos dois sistemas presidencialistas. Esse é um resultado que surpreende tendo em vista a tese recorrente acerca da relação entre número de partidos na coalizão e tempo de sobrevivência dos ministros no gabinete. Além disso, na Argentina os ministros saem em função de reforma ministerial até mais frequentemente que no Brasil, o que mostra que presidencialismo de partido único não dispensa reordenaçóes de gabinete para obter ou recuperar governabilidade.

A pesquisa mostra também que todos os números apresentados só fazem de fato sentido se forem examinados os contextos políticos e econômicos de cada governo separadamente e em cada país. Ou seja, se os constrangimentos institucionais năo explicam, é preciso considerar a dinâmica conjuntural para entender as diferenças, seja entre os dois casos nacionais analisados, seja entre os seus governos isoladamente. Se algum padrão pode ser encontrado, por mais frágil que seja essa conclusão, poderia ser formulado nos seguintes termos: governos de transiçấo da ditadura para a democracia, como Sarney e Alfonsín, e governos de crise política e econômica profunda, independentemente do tipo de presidencialismo em 
que operam, como Collor, Rousseff II, no Brasil, e De la Rúa e Duhalde, na Argentina, tendem a ser muito mais instáveis quanto à rotatividade dos seus ministros que governos que resolvem problemas crônicos de suas respectivas sociedades, ainda que temporariamente, como inflação e inclusão social, como os casos de Menem, N. Kirchner, C. Kirchner, FHC e Lula. Do mesmo modo, as razões fundamentais pelas quais ministros deixam o gabinete também devem ser vistas contextualmente. Sair do ministério para disputar eleiçóes é a regra em governos estáveis e de sucesso.

Nossos dados mostraram que, ao menos para os problemas específicos tratados neste artigo (sobrevivência ministerial e razóes de saida), a lógica política (multipartidária ou unipartidária) derivada dos desenhos institucionais pouco explica. A plena compreensão dos fatos aqui analisados exige a referência aos contextos históricos particulares e às dinâmicas políticas e econômicas conjunturais nacionais. Devemos, por isso, estudar mais as circunstâncias para ver o que podem revelar sobre o funcionamento dos presidencialismos, ao menos com base na experiência desses dois países.

\section{AGRADECIMENTOS}

Trabalho originalmente apresentado no XXXVI Congresso Internacional da Associação de Estudos Latino- Americanos (Lasa), em 2018. Em 2019, foi discutido no seminário "Presidente, Gabinete e Burocracias: o que a nova administração deve saber", organizado pelo grupo Presidência Institucional na América Latina (Prila), na Universidade Federal de Minas Gerais (UFMG), e apresentado no XIV Congreso Nacional de Ciencia Política da Sociedad Argentina de Análisis Político (SAAP). Os autores gostariam de agradecer aos pareceristas da Revista Brasileira de Ciências Sociais pelos comentários ao texto original e ao Conselho Nacional de Desenvolvimento Científico e Tecnológico (CNPq) e ao Consejo Nacional de Investigaciones Científicas y Técnicas (Conicet) pelo apoio financeiro à pesquisa.

\section{Notas}

1 Sobre a questấo do recrutamento de diferentes tipos de ministros, processos de formação de gabinetes, tempo de permanência e razôes de saída, ver, entre outros, uma ampla literatura: Alderman e Cross, 1979; Berlinski, Dewan e Dowding, 2007; Dowding e Dumont, 2009; González-Bustamante e Olivares, 2016b; Huber e Martinez-Gallardo, 2008; Indridason e Kam, 2008; Costa Pinto, Tavares de Almeida e Cotta, 2018; Davidsson e Bäck, 2019.

2 Houve, contudo, experiências de governos formados por coalizóes de partidos na Argentina, como a Alianza para el Trabajo, la Justicia y la Educación, resultado de uma junção entre a centenária Unión Cívica Radical (UCR) e a mais jovem Frente País Solidario (Frepaso), durante a presidência de Fernando De la Rúa, que governou o país entre 1999 e 2001, e a Cambiemos, entre o partido Propuesta Republicana (PRO), a UCR e a Coalición Cívica, no governo de Mauricio Macri, presidente até 2019. No entanto, mesmo nessas experiências de coalizão, o presidencialismo forte argentino permitiu ao presidente escolher seus ministros sem maiores concessôes aos demais partidos da coalizão. O funcionamento dessas duas experiências de governo foi bastante distinto em vários aspectos, mas nos dois casos quem venceu a disputa para ser candidato a presidente (De la Rúa, no primeiro caso, e Macri, no segundo) escolheu seus colaboradores no gabinete presidencial sem atribuir mais que dois ministérios a outro partido da coalizão de governo. Ver Dikenstein e Gené, 2014; Vommaro e Gené, 2017.

3 Muitos estudos se preocupam em identificar variáveis não institucionais ao estudar o processo de seleção de ministros em diversos tipos de sistemas de governo, notadamente variáveis de background social e de carreira. Ver, por exemplo, Tavares de Almeida e Costa Pinto, 2003; Cheibub, 1989; Huber e Martinez- Gallardo, 2004; Loureiro e Abrucio, 1999; Loureiro, Abrucio e Rosa, 1998; Luque Castillo, 2012; Nunes, 2013; Rose, 1971; Silveira, 2013; Tavares de Almeida, 2005; Indridason \& Kam, 2008; Codato e Franz, 2017; Tavares de Almeida, Costa Pinto \& Bermeo, 2005.

4 O número efetivo de partidos (NEP) na Câmara baixa no Brasil saltou de 2,9, em 1986, para 10,3 em 2010; depois para 13,6 em 2015 e, enfim, para impressionantes 16,3 em 2019. Ao contrário, na Argentina, esse número, apesar de crescente, foi muito mais estável: $2,39 \mathrm{em}$ 1985, subindo pouco a pouco para 3,4 em 2001. Em 2011, o NEP na Argentina era 4,1; em 2015, 4,9. Para o caso brasileiro, ver Freitas e Silva (2019); para o caso Argentino, ver Medina e Cao (2003, p. 11) e Tagina (2018) apud Ribeiro et al. (2018). Não há uma 
relação causal entre número de ministérios e número de partidos efetivos no Legislativo. Por exemplo, em 1986, durante o governo de José Sarney, o número efetivo de partidos era de apenas 2,9 (Santos, 2000) e o número de ministérios, 25; com Fernando Collor de Mello, em 1990, quando o NEP era de 9, o número de ministérios caiu para doze. A partir daí, porém, a tendência é que o aumento do NEP seja acompanhado pelo aumento do número de pastas, ao menos até o segundo governo de Dilma Rousseff. Após Michel Temer, esses números voltam a oscilar em sentido contrário. Assim, basicamente supóe-se que, quanto maior o número efetivo de partidos, maior a dificuldade para gerir a coalizão. Essa é, de resto, uma afirmação largamente amparada na literatura, como se verá na seção "Revisão da literatura". Sobre o número de ministérios de Sarney a Jair Bolsonaro, ver o levantamento em https:/www.estadao.com.br/ infograficos/politica,de-sarney-a-bolsonaro-veja-osministerios-de-cada-gestao,942125 (consultado em 19/2/2020). Segundo Gallagher (2019, pp. 9-10), o NEP na Câmara dos Deputados do Brasil é: 1990 (8,69), 1994 (8,16), 1998 (7,14), 2002 (8,47), 2006 (9,32), $2010(10,36), 2014(13,22)$. Para a Argentina: 2005 (6,49), 2011 (2,70), $2013(7,50)$.

5 Apesar disso, cada vez mais esse parece não ser o único critério. Expertise técnica no tema do portfólio ministerial, por exemplo, é também uma variável importante (Codato e Franz, 2018).

6 Já em 1984, Lijphart mostrou que, para quase toda a literatura da época, a durabilidade de gabinetes ministeriais estava inversamente associada ao número de partidos efetivos. Cf. Lijphart, 1984.

7 No caso dos presidencialismos de coalizão, já se sabe que a formação de gabinetes é apenas uma entre outras ferramentas usadas para a construção de coalizóes governamentais. Quanto a esse ponto, ver Chaisty, Cheeseman e Power, 2014. Sobre a formação de governos majoritários e minoritários nos presidencialismos da América Latina, cf. Figueiredo, Canello e Vieira, 2012.

8 Disponível em http://www.biblioteca.presidencia.gov.br/ presidencia/ex-presidentes, consultado em 19/2/2020.

9 Disponível em http://www.fgv.br/cpdoc/acervo/arquivo, consultado em 19/2/2020.

10 Disponível em https://www.wikipedia.org/, consultado em 19/2/2020.

11 O Brasil não tem marcos institucionais que definam, tão claramente como na Argentina, a estrutura dos seus gabinetes ministeriais. Durante a Primeira República, o gabinete ministerial era formado por dez ministérios. De 1930 a 1964, a estrutura não mudou muito, girando em torno de dez a treze pastas, tendo sido criados, durante esses anos, o Gabinete Civil, o Ministério da Saúde e o do Planejamento. Após o golpe de 1964, o número de ministérios aumentou sensivelmente, com a criação de pastas importantes, como Transporte, Comunicaçóes, Minas e Energias, além dos ministérios militares correspondentes às três Armas. A partir da redemocratização, o número de ministérios aumentou mais ainda e variou entre o mínimo de doze (Collor) e o máximo de 39 (Rousseff I). Sobre a Primeira República, ver Brasil, 1985. Para o período atual, acessar https:// www.estadao.com.br/infograficos/politica,de-sarney-abolsonaro-veja-os-ministerios-de-cada-gestao,942125, consultado em 19/2/2020.

12 É importante notar que, diferentemente de outros autores, não estamos tratando esse fato necessariamente como um "fracasso". Se a demissão por desempenho insatisfatório pode ser vista como tal, não é o caso quando se trata de saída para concorrer a uma eleiçáo ou para ocupar outro cargo importante no governo. Neste artigo, o evento específico se refere, portanto, à saída do ministro antes do término do mandato presidencial. Os que ficam até o final do mandato do presidente são os que "sobrevivem".

13 Por exemplo, no caso da Argentina, até a primeira presidência de Carlos Menem, o mandato presidencial era de seis anos (Alfonsín e Menem I); depois, com a reforma constitucional, o mandato passou a ser de quatro anos (Menem II, N. Kirchner, C. Kirchner I e C. Kirchner II). Entre Alfonsín e C. Kirchner II, porém, a Argentina teve um governo que terminou antes do prazo legal (De la Rúa) e outro interino, cuja eleição não passou pelo crivo das urnas e que também não conseguiu terminar seu mandato (Duhalde). Nesse caso, se medíssemos a estabilidade ministerial em meses, seria evidente que a presidentes mais instáveis caberiam ministros também mais instáveis, mesmo quando permanecessem no cargo durante todo o mandato do presidente a que serviram.

14 A fórmula, segundo Santos, é $X m=\frac{d . n}{m}$, em que $X m$ é a permanência média no cargo ministerial, $d$ é o número total de meses de duração de cada governo, $n$ representa o número de ministérios e $m$ significa o número de ministros. Cf. Santos, 1986, p. 119.

15 A fórmula ficaria, então, como $S g=\frac{X m}{L m a ́ x}$, em que $S g$ indica a estabilidade ministerial, $X m$ é a permanência média no cargo e $L_{\text {max }}$ representa a permanência máxima constitucional.

16 Para todos os dados usados nos cálculos dos Gráficos 2 e 3, ver Anexo.

17 Todos os percentuais de renovação ministerial citados a partir deste ponto foram retirados de gráficos de sobrevivência feitos governo a governo. Como a reprodução de todos esses gráficos deixaria a leitura 
demasiadamente pesada, optamos por retirá-los do texto.

18 Durante a crise entre dezembro de 2001 e janeiro de 2002, a Argentina contou com quatro presidentes. Neste artigo, levamos em consideração apenas os ministros nomeados pelo último deles, Eduardo Duhalde, cujos nomeados de fato exerceram suas funçóes. Os demais ficaram entre dois e oito dias na Presidência, o que fez com que muitos ministros não fossem sequer nomeados.

19 No caso do governo de Rousseff, qualquer tentativa de explicar a crise política não pode deixar de fazer referência à Operação Lava-Jato, deflagrada em março de 2014, que aprofundou o já grande impacto do judiciário brasileiro na cena política do país.

20 Mensalão foi a crise política decorrente da descoberta de um esquema de compra de votos no Congresso Nacional do Brasil, com vistas a facilitar a aprovação de projetos de interesse do governo. A crise política gerada pelo Mensaláo quase levou à apresentação de propostas de impedimento do presidente Luiz Inácio Lula da Silva. Ver https://www1.folha.uol.com.br/fsp/ brasil/fc0511200502.htm, consultado em 19/2/2020.

21 Resíduos padronizados são um indicativo de que os valores encontrados excedem os valores esperados. Ou seja, dada uma distribuição probabilística ideal, o resíduo padráo denota o dado que foge à probabilidade esperada estatisticamente, para mais ou para menos na distribuição. Aqui os resíduos com valores acima de 1,96 ou abaixo de $-1,96$ indicam que há concentração de determinados grupos além da expectativa estatística quando o intervalo de confiança é de $95 \%$. Ver Pestana e Gageiro, 2008.

22 Uma hipótese contrária à nossa $H 1$ pode ser a de que, na Argentina, há uma instabilidade ministerial táo grande quanto no Brasil, já que, tendo o presidente maior liberdade de ação, pode trocar os ministros do gabinete a seu bel-prazer, sem qualquer constrangimento imposto por uma coalizão da qual depende. De fato, esse pode ser o caso aqui, já que os dados que apresentamos sobre estabilidade ministerial nos dois países são semelhantes e, ademais, nos dois países a reforma ministerial é uma importante razão de saída dos ministros. Essa hipótese nos foi sugerida por um dos pareceristas da RBCS.

23 Essas disputas internas, é importante enfatizar, não estavam associadas aos conflitos entre membros de diferentes partidos, mas aos ministros pertencentes às várias fraçóes internas do mesmo partido (UCR, partido do presidente) e à sua relaçáo de proximidade ou distância com o primeiro mandatário. Essa é a única experiência multipartidária que analisamos para a Argentina neste artigo (a outra é a de Macri, fora da nossa amostra); porém, o gabinete multipartidário não apresenta variantes relevantes em relação ao restante dos gabinetes do período, visto que a distribuição de ministros foi muito desigual entre as duas forças que constituíam a Alianza: o presidente decidiu a totalidade dos ministros e conferiu apenas dois portfólios à Frepaso, que tinha um papel minoritário no Executivo (Dikenstein e Gené, 2014).

24 No Brasil, as eleiçôes municipais de 1992 foram postergadas e só ocorreram no governo de Itamar Franco. As eleiçóes municipais de 2016 ocorreram normalmente em outubro, com Rousseff já afastada do cargo.

\section{BIBLIOGRAFIA}

ABRANCHES, Sérgio. (1988), "Presidencialismo de coalizão: o dilema institucional brasileiro". Dados, 31 (1): 5-34.

ALDERMAN, Robin Keath \& CROSS, John Arthur. (1979), "Ministerial reshuffles and the civil service". British Journal of Political Science, 9 (1): 41-65.

ALTMAN, David. (2000), "The politics of coalition formation and survival in multiparty presidential democracies: the case of Uruguay, 1989-1999”. Party Politics, 6 (3): 259-283.

AMORIM NETO, Octavio \& SAMUELS, David. (2010), "Democratic regimes and cabinet politics: a global perspective". Revista Ibero-Americana de Estudios Legislativos, 1 (1): 10-23.

AMORIM NETO, Octavio. (1994), "Formação de gabinetes presidenciais no brasil: coalizão versus cooptação". Nova Economia, 4 (1): 9-34.

AMORIM NETO, Octavio. (2000), "Gabinetes presidenciais, ciclos eleitorais e disciplina legislativa no Brasil". Dados, 43 (3): 479-519.

ARELLANO GONZÁLEZ, Juan Carlos; TORO MAUREIRA, Sergio \& NOVOA OCARES, Romina. (2018), "Sobrevivencia ministerial en Chile: partidos, coaliciones y presidencialismo desde 1830 a 1973". Revista Chilena de Derecho y Ciencia Política, 9 (1): 132-163.

BATISTA, Mariana. (2013), "O poder no executivo: uma análise do papel da presidência e dos ministérios no presidencialismo de coalizão brasileiro (1995-2010)”. Opinião Pública, 19 (2): 449-473.

BERLINSKI, Samuel; DEWAN, Torun \& DOWDING, Keith. (2007), "The length of ministerial tenure 
in the United Kingdom, 1945-97". British Journal of Political Science, 37 (2): 245-262.

BERROTARÁN, Patricia. (2012), "Guiso de liebre sin liebre: Estado, burocracias y peronismo", in M. Plotkin \& E. Zimermann (org.), Las prácticas del Estado: politica, sociedad y elites estatales en la Argentina del siglo XX, Buenos Aires, Edhasa, pp. 131-156.

BLONDEL, Jean; MÜLLER-ROMMEL, Ferdinand \& MALOVÀ, Darina. (2007), Governing new European democracies. Londres, Palgrave Macmillan.

BRASIL. Senado Federal. (1985), O governo presidencial do Brasil (1889-1930). Guia administrativo do Poder Executivo no periodo da República Velha. Brasília/Rio de Janeiro, Senado Federal/Fundaçáo Casa de Rui Barbosa.

CAMERLO, Marcelo. (2013), "Gabinetes de partido único y democracias presidenciales. indagaciones a partir del caso argentino". América Latina Hoy, 64: 119-142.

CAMPIONE, Daniel. (2007), Origenes estatales del peronismo. Buenos Aires, Miño y Dávila Editores.

CHAISTY, Paul; CHEESEMAN, Nic \& POWER, Timothy. (2014), "Rethinking the 'presidentialism debate': conceptualizing coalitional politics in cross-regional perspective". Democratization, 21 (1): 72-94.

CHEIBUB, Zairo. (1989), "A carreira diplomática no Brasil: o processo de burocratizaçáo do Itamarati". Revista de Administração Pública, 23 (2): 97-128.

CODATO, Adriano \& FRANZ, Paulo. (2017), "Recrutamento ministerial no Brasil: comparando as presidências de FHC e Lula". Revista Eletrônica do Programa de Pós-Graduação da Câmara dos Deputados, 10 (22): 44-62.

CODATO, Adriano \& FRANZ, Paulo. (2018), "Ministros-técnicos e ministros-políticos nos governos do PSDB e do PT". Revista de Administração Pública, 52 (5): 776-796.

CODATO, Adriano; PERISSINOTTO, Renato \& GENÉ, Mariana. (2020), Database: Ministers in Argentina and Brazil (1983-2016). figshare. Dataset. https://figshare.com/articles/Untitled_ Item/11881221/2, consultado em 21/02/2020
COSTA PINTO, Antonio \& TAVARES DE ALMEIDA, Pedro. (2009), "Portugal: the primacy of 'independents', in K. Dowding \& P. Dumont (orgs.), The selection of ministers in Europe: hiring and firing, Londres/Nova York, Routledge, pp. 147-158.

COSTA PINTO, Antonio; TAVARES DE ALMEIDA, Pedro \& COTTA, Maurizio (org.). (2018), Technocratic ministers and political leadership in European democracies. Londres, Palgrave Macmillan.

DAVIDSSON, Johan Bo \& BÄCK, Hanna. (2019), "Selecting ministers in times of crisis: a historical analysis of the role of intra-party politics and union background in Swedish cabinet appointments (1917-2014)". Political Studies, 67 (4): 932-954.

DE LUCA, Miguel. (2011), "Del príncipe y sus secretarios. Cinco apuntes sobre gabinetes presidenciales en la Argentina reciente", in A. Malamud \& M. De Luca (org.), La politica en tiempos de Kirchner, Buenos Aires, Eudeba, pp. 37-48.

DE RIZ, Liliana \& SMULOVITZ, Catalina. (1991), "Instituciones y dinámica política. El presidencialismo argentino", in D. Nohlen \& L. De Riz (orgs.), Reforma institucional y cambio politico, Buenos Aires, Legasa-CEDES, pp. 137-157.

DIKENSTEIN, Violeta \& GENÉ, Mariana. (2014), "De la creación de la Alianza a su vertiginosa implosión. Reconfiguraciones de los elencos políticos en tiempos de crisis", in A. Pucciarelli \& A. Castellani (org.), Los años de la alianza: la crisis del orden neoliberal, Buenos Aires, Siglo XXI, pp. 35-79.

DOWDING, Keith \& DUMONT, Patrick. (2009), "Structural and strategic factors affecting the hiring and firing of ministers", in K. Dowding \& P. Dumont (org.), The selection of ministers in Europe: hiring and firing, Londres/Nova York, Routledge, pp. 1-20.

FIGUEIREDO, Argelina; CANELLO, Júlio \& VIEIRA, Marcelo. (2012), "Governos minoritários no presidencialismo latino-americano: determinantes institucionais e políticos", Dados, 55 (4): 839-875.

FREITAS, Andréa \& SILVA, Glauco Peres da. (2019), "Das manifestaçōes de 2013 à eleição de 2018 no 
Brasil: buscando uma abordagem institucional”. Novos Estudos Cebrap, 38 (1): 137-155.

GALLAGHER, Michael. (2019), Election indices dataset. Disponível em https://www.tcd.ie/ Political_Science/people/michael_gallagher/ ElSystems/Docts/ElectionIndices.pdf, consultado em 21/2/2020.

GENÉ, Mariana. (2014), Al interior de la politica. Trayectorias, destrezas y modos de hacer politica en el Ministerio del Interior (1983-2007). Tese de doutorado. Universidad de Buenos Aires/ École des Hautes Études en Sciences Sociales, Buenos Aires.

GENÉ, Mariana. (2016), "Los elencos del presidente. Expertise, destrezas políticas y anclajes sociales en el gabinete de ministros (Argentina, 1983-2011)", Anais do X Encontro da Associação Brasileira de Ciência Politica, Belo Horizonte, p. 1-22.

GENÉ, Mariana; HEREDIA, Mariana \& PERELMITER, Luisina. (2015), "La acción estatal en plural. Ministerios, racionalidades y desafíos de gobierno en la Argentina democrática”, Anales del XII Congreso Nacional de la Sociedad Argentina de Análisis Politico, Mendoza, pp. 1-26.

GIORGI, Guido Ignacio. (2014), "Los factores 'extrapolíticos' de la carrera política: una aproximación a las sociabilidades de los ministros de la nación en la argentina (1854-2011)". Politica. Revista de Ciência Política, 52 (2): 243-275.

GONZÁLEZ-BUSTAMANTE, Bastián \& OLIVARES, Alejandro. (2016a), "A rotatividade de subsecretários dos ministérios no Chile (19902014)". Observatory of Social and Political Elites of Brazil, 3 (5): 1-16 (newsletter).

GONZÁLEZ-BUSTAMANTE, Bastián \& OLIVARES, Alejandro. (2016b), "Cambios de gabinete y supervivencia de los ministros en Chile durante los gobiernos de la Concertación (1990-2010)", Colombia Internacional, 87: 81-108.

HANSEN, Martin Einar; KLEMMENSEN, Robert; HOBOLT, Sara \& BÄCH, Hanna. (2013), "Portfolio saliency and ministerial turnover: dynamics in Scandinavian postwar cabinets", Scandinavian Political Studies, 36 (3): 227-248.
HEREDIA, Mariana. (2015), Cuando los economistas alcanzaron el poder (o cómo se gestó la confianza em los expertos). Buenos Aires, Siglo XXI Editores.

HUBER, John D. \& MARTINEZ-GALLARDO, Cecilia. (2004), "Cabinet instability and the accumulation of experience: the French fourth and fifth republics in comparative perspective", British Journal of Political Science, 34 (1): 27-48.

HUBER, John D. \& MARTINEZ-GALLARDO, Cecilia. (2008), "Replacing cabinet ministers: patterns of ministerial stability in parliamentary democracies", American Political Science Review, 102 (2): 169-180.

INÁCIO, Magna. (2013), "Escogiendo ministros y formando políticos: los partidos en gabinetes multipartidistas". América Latina Hoy, 64: 41-66.

INDRIDASON, Indridi \& KAM, Christopher. (2008), "Cabinet reshuffles and ministerial drift". British Journal of Political Science, 38 (4): 621-656.

KERBY, Mathew. (2015), "Canada: ministerial careers", in K. Dowding \& P. Dumont (org.), The selection of ministers around the world, Londres/ Nova York, Routledge, pp. 264-282.

LEVITSKY, Steven \& MURILLO, María Victoria. (2008), "Argentina: from Kirchner to Kirchner". Journal of Democracy, 19 (2): 16-30.

LIJPHART, Arend. (1984), "Measures of cabinet durability: a conceptual and empirical evaluation". Comparative Political Studies, 17 (2): 265-279.

LOUREIRO, Maria Rita \& ABRUCIO, Fernando Luiz. (1999), "Política e burocracia no presidencialismo brasileiro: o papel do Ministério da Fazenda no primeiro governo Fernando Henrique Cardoso". Revista Brasileira de Ciências Sociais, 14 (41): 69-89.

LOUREIRO, Maria Rita; ABRUCIO, Fernando \& ROSA, Carlos Alberto. (1998), "Radiografia da alta burocracia federal brasileira: o caso do Ministério da Fazenda”. Revista do Serviço Público, 49 (4): 46-82.

LUQUE CASTILLO, Francisco Javier. (2012), Los ministros de Hacienda en España (19011986): perfil sociopolitico e influencia. Tese de doutorado. Departamento de Ciencia Política y de la Administración, Universidad de Granada, Granada. 
MEDINA, Juan Abal \& CAO, Julieta Suárez. (2003), "Partisan competition in Argentina. From closed and predictable to open and unpredictable", Annals of 2003 Meeting of the Latin American Studies Association, Dallas, pp. 1-21.

NOVARO, Marcos. (2006), Historia de la Argentina contemporánea: de Perón a Kirchner. Buenos Aires, Edhasa.

NUNES, Felipe Abreu. (2013), “'One country, three systems': the recruitment of administrative elites in Portugal, 1999-2009", Portuguese Journal of Social Science, 12 (2): 163-178.

OlliER, María Matilda \& PALUMBO, Pablo. (2016), “¿Caso testigo o caso único? Patrones de la formación de gabinete en el presidencialismo argentino (1983-2015)", Colombia Internacional, 87: 53-80.

PERSELLO, Ana Virginia. (2007), Historia del radicalismo. Buenos Aires, Edhasa.

PESTANA, Maria Helena \& GAGEIRO, João Nunes. (2008), Análise de dados para ciências sociais: a complementaridade do SPSS. Lisboa, Sílabo.

POMARES, Julia; LEIRAS, Marcelo; PAGE, María; ZÁRATE, Soledad \& ABDALA, María Belén. (2014), "Los caballeros de la mesa chica. La lógica de designación de los gabinetes desde 1983", Documentos de Políticas Públicas, 139: 1-12.

PUCCIARELLI Alfredo (coord.). (2011), Los años de Menem: la construcción del orden neoliberal. Buenos Aires, Siglo XXI.

PUCCIARELLI, Alfredo \& CASTELLANI, Ana (orgs.). (2017), Los años del kirchnerismo: la disputa hegemónica tras la crisis del orden neoliberal. Buenos Aires, Siglo XXI.

QUIROZ FLORES, Alejandro. (2009), "The political survival of foreign ministers", Foreign Policy Analysis, 5 (2): 117-133.

RIBEIRO, Pedro Floriano; LOCATELLI, Luís Gustavo Bruno; ASSIS, Pedro Paulo \& LEVEGUEN, Brina Deponte. (2018), "Mapping democratic innovations in Latin American parties". Disponível em https:// www.researchgate.net/publication/327582264, consultado em 18/2/2020.

RINESI, Eduardo \& VOMMARO, Gabriel. (2007), "Notas sobre la democracia, la representación y algunos problemas conexos", in E. Rinesi; G. Nardachione \& G. Vommaro, Los lentes de Victor Hugo: transformaciones politicas y desafios teóricos en la Argentina reciente, Buenos Aires, Prometeo-UNGS, pp. 419-472.

ROSE, Richard. (1971), "The making of cabinet ministers". British Journal of Political Science, 1 (4): 393-414.

SANTOS, Fabiano. (2000), "Escolhas institucionais e transição por transação: sistemas políticos de Brasil e Espanha em perspectiva comparada", Dados, 43 (4): 637-669.

SANTOS, Wanderley Guilherme dos. (1986), Sessenta e quatro: anatomia da crise. Rio de Janeiro, Vértice.

SCHARFENKAMP, Katrin. (2018), "The effects of bridging business and politics: a survival analysis of German Federal ministers". European Journal of Political Economy, 55: 433-454.

SIGAL, Silvia \& KESSLER, Gabriel. (1997), "La hiperinflación en Argentina: comportamientos y representaciones sociale", in $\mathrm{D}$. Cantón \& $\mathrm{R}$. Jorrat (orgs.), La investigación social hoy, Buenos Aires, CBC-UBA, pp. 155-187.

SILVEIRA, Pedro Miguel Alegria. (2013), Os secretários de estado da democracia portuguesa: perfis sociopoliticos e carreiras governativas. Dissertaçāo de mestrado. Faculdade de Ciências Sociais e Humanas, Universidade Nova de Lisboa, Lisboa.

STAWSKI, Martín. (2012), "Del equipo de asalto a la consolidación: estado, elites y economía durante el primer peronismo, 1946-1955", in M. B. Plotkin \& E. Zimmermann (org.), Las prácticas del estado. Politica, sociedad y elites estatales en la Argentina del siglo XX, Buenos Aires, Edhasa, pp. 93-129.

TAGINA, María Luisa. (2018), "Argentina, kirchnerismo y después: la alternancia electoral de 2015", in M. Alcántara; D. Buquet \& M. L. Tagina (org.), Elecciones y partidos politicos en América Latina en el cambio de ciclo, Madri, Centro de Investigaciones Sociológicas, pp. 21-45.

TAVARES DE ALMEIDA, Pedro \& COSTA PINTO, Antonio. (2003), "Portuguese ministers, 18511999: social background and paths to power", in P. Tavares de Almeida; A. Costa Pinto \& N. Bermeo (org.), Who governs Southern Europe? 
Regime Changing and Ministerial Recruitment (1850-2000), Londres/Portland, Frank Cass Publishers, pp. 4-37.

TAVARES DE ALMEIDA, Pedro. (2005), “The Portuguese administrative elite (1851-1910)". Revista de História das Ideias, 26: 439-462.

TAVARES DE ALMEIDA, Pedro; COSTA PINTO, Antonio \& BERMEO, Nancy (org.). (2005), Who governs Southern Europe? Regime changing and ministerial recruitment (1850-2000). Londres/ Portland, Frank Cass Publishers.
TORRE, Juan Carlos. (1999), "El peronismo como solución y como problema”, in J. C. Torre et al., Entre el abismo y la ilusión: peronismo, democracia y mercado, Buenos Aires, Grupo Editorial Norma, pp. 41-50.

VASSELAI, Fabricio. (2009), "Nomeações ministeriais e importância partidária na democracia de 194664: análises comparativas em relaçáo à democracia atual", Perspectivas, 35: 173-210.

VOMMARO, Gabriel \& GENÉ, Mariana. (2017), "Argentina: el año de Cambiemos", Revista de Ciencia Politica (Santiago), 37 (2): 231-254. 


\section{QUANDO O CONTEXTO \\ IMPORTA: ANÁLISE DO TURNOVER MINISTERIAL NA ARGENTINA E NO BRASIL APÓS A REDEMOCRATIZAÇÁO}

\section{Renato Perissinotto, Adriano Codato and Mariana Gené}

Palavras-chave: Recrutamento ministerial; Demissão ministerial; Método Kaplan-Meier; Presidencialismo de coalizão; Presidencialismo de partido único.

Este artigo testa duas hipóteses sobre sobrevivência ministerial em dois tipos de regimes presidenciais, o presidencialismo de coalizão (Brasil) e o de partido único (Argentina). Primeiro, supóe-se que ministros no Brasil teriam tempo de vida no cargo menor que na Argentina pela necessidade de acomodar demandas da coalizão partidária. Em seguida, sugere-se que as razões de saída de ministros seriam diferentes justamente porque as lógicas de nomeação são distintas nos dois presidencialismos. A primeira hipótese é avaliada por meio dos testes de sobrevivência Kaplan-Meier. A segunda hipótese é analisada por meio da identificaçáo das razóes de saída dos ministros em fontes primárias. A literatura enfatiza que arranjos institucionais afetam o tempo de permanência dos ministros nos seus cargos e as razôes pelas quais são demitidos, mas concluímos que somente a inclusáo dos contextos políticos e econômicos de cada período presidencial nos ajuda a entender plenamente a dinâmica da sobrevivência ministerial em cada país.

\section{WHEN CONTEXT MATTERS: ANALYSIS OF THE MINISTERIAL TURNOVER IN ARGENTINA AND BRAZIL AFTER REDEMOCRATIZATION}

\section{Renato Perissinotto, Adriano Codato and Mariana Gené}

Keywords: Ministerial recruitment; Ministerial dismissal; Kaplan-Meier method; Coalition presidentialism; One-party presidentialism.

This article tests two hypotheses concerning ministerial survival in two types of presidential regimes, namely coalition presidentialism (Brazil) and single party presidentialism (Argentina). First, it is assumed that ministers in Brazil would present a shorter life span in their positions than in Argentina, due to the need to accommodate party coalition demands. Subsequently, it is suggested that the reasons for ministers leaving their positions would be different precisely because the appointment logics of both presidential regimes are distinct. The first hypothesis is assessed by applying Kaplan-Meier survival tests. The second hypothesis is analyzed by identifying the reasons ministers left their positions, using primary sources. The literature emphasizes that institutional arrangements affect minister permanence lengths in their positions and the reasons by which they are dismissed, although we conclude that only the inclusion of the political and economic contexts of each presidential period aid towards a full understanding of ministerial survival dynamics in each country.
QUAND LE CONTEXTE EST IMPORTANT: ANALYSE DU REMANIEMENT MINISTÉRIEL EN ARGENTINE ET AU BRÉSIL APRÈS LA REDÉMOCRATISATION

\author{
Renato Perissinotto, Adriano Codato et \\ Mariana Gené
}

Mots-clés: Recrutement ministériel; Démission ministérielle; Méthode Kaplan-Meier; Présidentialisme de coalition; Présidentialisme à parti unique.

Cet article analyse deux hypothèses sur la «survie ministérielle » dans deux types de régimes présidentiels, le présidentialisme de coalition (Brésil) et le présidentialisme de parti unique (Argentine): Premièrement, les ministres brésiliens resteraient moins longtemps à leur poste que leurs collègues argentins en fonction des demandes de la coalition des partis. Deuxièmement, les raisons des départs des ministres des deux pays ne sont pas les mêmes à cause de logiques de nomination différentes dans les deux régimes. La première hypothèse est évaluée par l'estimateur de Kaplan-Meier, la seconde par l'identification des motifs ayant entraîné leur sortie du gouvernement. Si les études indiquent que les arrangements institutionnels affectent la durée du mandat des ministres et les raisons de leur révocation, nous pensons que seule l'inclusion des contextes politico-économiques de chaque période présidentielle aide à comprendre pleinement la dynamique de la survie ministérielle dans chaque pays. 


\section{Anexo 1.}

Dados para os cálculos do coeficiente de instabilidade ministerial

\begin{tabular}{|c|c|c|c|c|c|c|c|}
\hline Presidentes & $\begin{array}{c}\text { Tempo de } \\
\text { permanência } \\
\text { do } \\
\text { presidente } \\
\text { (meses) (1) }\end{array}$ & $\begin{array}{l}\text { Tempo de } \\
\text { permanência } \\
\text { máxima } \\
\text { constitucional } \\
\text { (meses) (2) }\end{array}$ & $\begin{array}{c}\text { N. } \\
\text { ministros } \\
(3)\end{array}$ & $\begin{array}{c}\mathrm{N} . \mathrm{de} \\
\text { ministérios } \\
(4)\end{array}$ & $\begin{array}{c}\text { Duraçáo } \\
\text { média dos } \\
\text { mandatos } \\
\text { ministeriais } \\
\{(1 \times 4) / 3\}(5)\end{array}$ & $\begin{array}{c}\text { Estabilidade } \\
\text { ministerial } \\
\text { comparada } \\
\{5 / 2\}(6)\end{array}$ & $\begin{array}{c}\text { Coeficiente } \\
\text { do } \\
\text { indicador } \\
\text { de } \\
\text { instabilidade } \\
\{1-(5 / 2)\} \\
\end{array}$ \\
\hline Alfonsín & 67 & 72 & 24 & 8 & 22,3 & 0,31 & 0,69 \\
\hline Menem I & 72 & 72 & 30 & 9 & 21,5 & 0,30 & 0,70 \\
\hline Menem II & 53 & 48 & 18 & 9 & 26,5 & 0,55 & 0,45 \\
\hline De la Rúa & 24 & 48 & 21 & 11 & 12,7 & 0,27 & 0,73 \\
\hline Duhalde & 17 & 48 & 14 & 11 & 13,1 & 0,27 & 0,73 \\
\hline N. Kirchner & 54 & 48 & 19 & 11 & 31,5 & 0,66 & 0,34 \\
\hline C. Kirchner I & 48 & 48 & 25 & 16 & 30,6 & 0,64 & 0,36 \\
\hline C. Kirchner II & 48 & 48 & 25 & 17 & 32,6 & 0,68 & 0,32 \\
\hline Média & & & & & & & 0,54 \\
\hline Sarney & 60 & 60 & 78 & 30 & 23,1 & 0,38 & 0,62 \\
\hline Collor & 30 & 48 & 45 & 27 & 18,0 & 0,38 & 0,63 \\
\hline Franco & 24 & 24 & 55 & 29 & 12,7 & 0,53 & 0,47 \\
\hline FHC I & 48 & 48 & 50 & 31 & 29,8 & 0,62 & 0,38 \\
\hline FHC II & 48 & 48 & 56 & 28 & 24,0 & 0,50 & 0,50 \\
\hline Lula I & 48 & 48 & 65 & 35 & 25,8 & 0,54 & 0,46 \\
\hline Lula II & 48 & 48 & 58 & 35 & 29,0 & 0,60 & 0,40 \\
\hline Rousseff I & 48 & 48 & 73 & 35 & 23,0 & 0,48 & 0,52 \\
\hline Rousseff II & 16 & 48 & 43 & 32 & 11,9 & 0,25 & 0,75 \\
\hline Média & & & & & & & 0,52 \\
\hline
\end{tabular}

Fonte: Codato, Perissinotto e Gené, 2020. 